Florida International University FIU Digital Commons

$11-19-1996$

\title{
The application of a multimedia system to the tourist guide of the Miami International Airport
}

Ying-Yuang Chen

Florida International University

DOI: $10.25148 /$ etd.FI14060181

Follow this and additional works at: https://digitalcommons.fiu.edu/etd

Part of the Computer Sciences Commons

\section{Recommended Citation}

Chen, Ying-Yuang, "The application of a multimedia system to the tourist guide of the Miami International Airport" (1996). FIU Electronic Theses and Dissertations. 2149.

https://digitalcommons.fiu.edu/etd/2149 
Miami, Florida

The Application of a Multimedia System to the Tourist Guide of the Miami International Airport

A thesis submitted in partial satisfaction of the

requirements for the degree of

MASTER OF SCIENCE

IN

COMPUTER SCIENCE

by

Ying-Yuang Chen 
To: Dean Arthur Herriott

College of Arts and Science

This thesis, written by Ying-Yuang Chen, and entitled The Application of a Multimedia System to the Tourist Guide of the Miami International Airport, having been approved in respect to style and intellectual content, is referred to you for judgement.

We have read this thesis and recommend that it be approved.

Nagarajan Prabhakaran

Yi Deng

Wei Sun, Major Professor

Date of Defense: November 19, 1996

This thesis of Ying-Yuang Chen is approved.

Dean Arthur W. Herriott

College of Arts and Sciences

Dr. Richard L. Campbell

Dean of Graduate Studies

Florida International University, 1996 


\section{ACKNOWLEDGEMENTS}

I would like to express my appreciation and gratitude to guidance committee for initiating, supervising, and contributing to this thesis; To

Professor Dr. Wei Sun for being my major Professor, introducing me to the world of interactive multimedia applications, initiating this work, and giving important advice and directions; to Professor Dr. Nagarajan

Prabhakaran and Professor Dr. Yi Deng for kindly joining my committee and giving valuable suggestions.

My appreciation also goes to Hsiao-Chih Shan and De-Wei Yang for their help, support and stimulating conversations in video filming and manuscript refinement process.

Finally, my deepest gratitude goes to my parents and my wife Chia-Li Chen, for their love, support, understanding and encouragement. 


\title{
ABSTRACT OF THE THESIS
}

The Application of a Multimedia System to the Tourist Guide of the

\section{Miami International Airport}

\author{
by \\ Ying-Yuang Chen \\ Florida International University, 1996

\section{Professor Wei Sun, Major Professor}

This project is to present a multimedia system designed for Miami International Airport as a tourist guide for passengers and to demonstrate the functionalities and facilities of the airport.

The project is based on an inexpensive integrated and comprehensive multimedia environment. The major components of the environment consist of (1) a low cost PC 386/486 with only ISA bus and IDE hard drive, (2) a high quality and high performance add-on real-time video/audio codec board (30/25 fps for NTSC/PAL video and synchronized audio sampled at $22 \mathrm{KHz}$ ), (3) software packages including interactive utility programs to record, playback and edit real-time video/audio source and also dynamic and static function libraries for application program development under MS window and DOS, (4) authoring tool kits to help generate multimedia applications. The significance of having such a low-cost, high performance, and integrated environment lies in its potential for an easy and large-scale deployment. 


\section{TABLE OF CONTENT}

1.Introduction

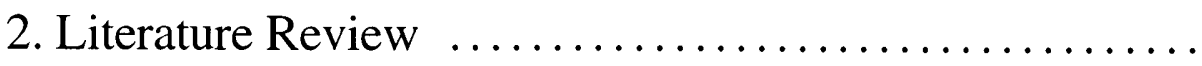

2.1. The effectiveness of the audio/video multimedia

technology in computer-human interface.

2.2. The application development of the multimedia

technology in business application. ..............

2.3. The development of the multimedia technology in

education application

2.4. The development of the multimedia technology in home application

2.5. Future trends of multimedia technology

3. Instrumentation

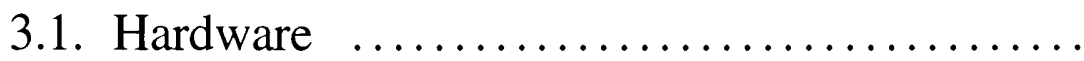

3.1.1. JMC550 Board

3.1.2 Installing JMC550 board to an IBM Compatible PC.

3.1.3 Media Vision's Pro AudioSpectrum16 installed in a Macintosh Quadra 800 
3.2.1 JMC-550 software package $\ldots \ldots \ldots \ldots \ldots$

3.2.2 SoundEdit Pro $\ldots . . . \ldots \ldots \ldots \ldots \ldots$

4. Multimedia application design using MDK authoring tools

4.1. Producing a Multimedia Application using MDK authoring tools. ...................... 30

4.1.1. System design $\quad \ldots . \ldots \ldots \ldots \ldots \ldots \ldots . . . \ldots$

4.1.2. Recording of the messages .............. 34

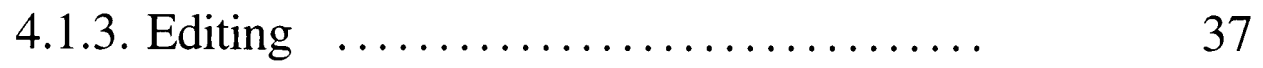

4.1.4. Maintenance ...................... $\quad 37$

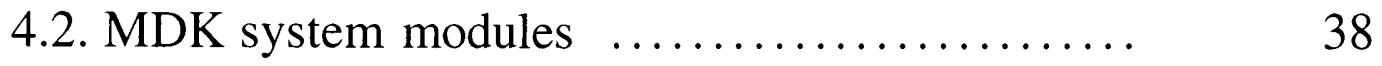

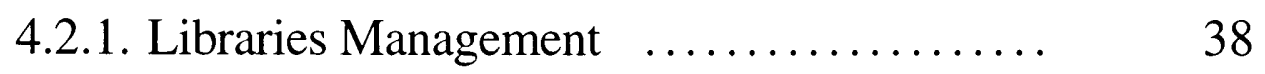

4.2.1.1 Main Menu .................. 38

4.2.1.2 Tools bar .................... 39

4.2.1.3 Button library $\ldots \ldots \ldots \ldots \ldots \ldots . \quad 40$

4.2.1.4 Literal Library $\ldots . \ldots \ldots \ldots \ldots \ldots . \quad 41$

4.2.1.5 Graphic library $\ldots \ldots \ldots \ldots \ldots \ldots . \quad 43$

4.2.1.6 Sound Library ................. 44

4.2.1.7 Video Library $\ldots . . \ldots \ldots \ldots \ldots . . . . .45$

4.2.2 MDK Editor $\ldots . \ldots \ldots \ldots \ldots \ldots \ldots . . . \ldots$

4.2.2.1 Structure window $\ldots . \ldots \ldots \ldots \ldots . \quad 46$

4.2.2.2 MDK Tool box $\ldots \ldots \ldots \ldots \ldots \ldots . \quad 48$ 
5. Design and Implementation $\ldots \ldots \ldots \ldots \ldots \ldots \ldots \ldots . \ldots . \ldots$

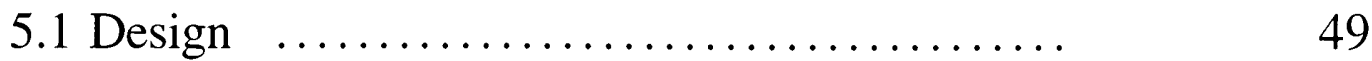

5.2 Implementation $\ldots \ldots \ldots \ldots \ldots \ldots \ldots \ldots \ldots \ldots . \ldots . \ldots$

5.2 .1 Video Clip Production $\ldots . . \ldots \ldots \ldots \ldots \ldots . \ldots$

5.2.2 Button Art Work $\ldots \ldots \ldots \ldots \ldots \ldots \ldots . . \ldots 2$

5.3.3 Bitmap Image Art Work $\ldots \ldots \ldots \ldots \ldots \ldots . \ldots 4$

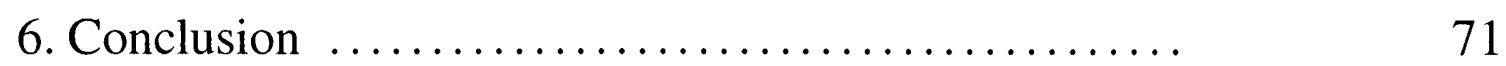

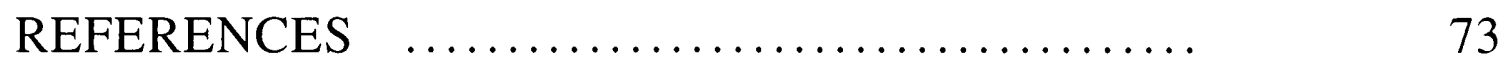




\section{LIST OF FIGURES}

Figure 1. A Block Diagram of the Board

Figure 2. The connection between VGA adapter and JMC550 $\ldots .25$

Figure 3. Connection of Video and Audio to JMC-550 ...... 26

Figure 4. The main screen of the hotel multimedia application $\quad \ldots \quad 32$

Figure 5. Button library browse $\ldots \ldots \ldots \ldots \ldots \ldots \ldots \ldots . . \ldots, 41$

Figure 6. Literal library Browse $\ldots \ldots \ldots \ldots \ldots \ldots \ldots \ldots . . \ldots, 42$

Figure 7. Edit window for text library $\ldots \ldots \ldots \ldots \ldots \ldots \ldots$

Figure 8 . Graphic library browse $\ldots \ldots \ldots \ldots \ldots \ldots \ldots . \ldots \ldots$

Figure 9. Sound library browse $\ldots \ldots \ldots \ldots \ldots \ldots \ldots \ldots$

Figure 10. Video library browse $\ldots \ldots \ldots \ldots \ldots \ldots \ldots \ldots . . \ldots$

Figure 11. MDK Structure Window $\ldots \ldots \ldots \ldots \ldots \ldots \ldots . . . \ldots$ 
Figure 12. Structure Diagram of Introduction to MIA $\ldots \ldots \ldots . \quad 51$

Figure 13. Main Screen of this application $\quad \ldots \ldots \ldots \ldots \ldots \ldots . . \ldots$

Figure 14. Video Screen $\quad \ldots . \ldots \ldots \ldots \ldots \ldots \ldots \ldots \ldots . \ldots . \ldots . \ldots$

Figure 15. Bitmap Screen with buttons $\ldots \ldots \ldots \ldots \ldots \ldots \ldots$

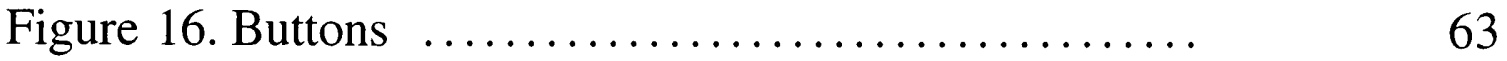

Figure 17. Directory map template $\ldots \ldots \ldots \ldots \ldots \ldots \ldots . . . \ldots 5$

Figure 18. Restaurants and Restroom directory map ........ 67

Figure 19. Duty Free Shop and Pharmacy directory map. $\ldots \ldots .68$

Figure 20. Moving Workway and Elevators directory map $\quad \ldots \ldots \quad 69$

Figure 21. Handicapped Parking and TDD Phone directory map. $\quad .70$ 


\section{Introduction}

Multimedia computing had become more and more important because it can dramatically improve applications in many areas. Audio and video can get us experiencing the information presented more closely than can normally be achieved by simple text and graphic (Fetterman, 1993). Previous usage of video restricted the user's interaction with the video to traveling along the paths predetermined by the author of the program. With the help of multimedia application, user can quickly change their level of interaction from passively watching a movie to actively choose the desired section of the information.

In recent years multimedia applications were brought into PC's and workstations because of the advances in hardware technologies such as faster CPU, bigger, inexpensive storage, wider bandwidth data bus, audio/video capturing/digitizing and playback devices with a compression / decompressions processor and the standardization of video/audio extensions (Fox, 1989) .

In addition, multimedia application can be used in many ways: Multimedia applications include Computer-Based Training (CBT) 
applications, product documentation, and maintenance manuals that deliver task-specific information to individuals when, where and how it is needed. These computer-based graphic program and device give organizations a major opportunity for reducing the cost of using real equipments for training (Fetterman, 1993; Ripley, 1989).

Multimedia applications can also be used in computer-aided graphic design, animated graphics and video presentation for business and sales, analog video editing, video data analysis, multimedia communications, interactive product documentaries and in video production; visual aids with interactive multimedia technologies can help a learning process to aid instruction and education (CAI/CAE) (Davenport, 1989;Ripley, 1989); home multimedia games and applications, which can display real video action as well as animation, are quite attractive and have a very large market potential (Dixon, 1989; Ripley, 1989).

Generally speaking, the entire computer industry will benefit from the use of full-motion, video-based multimedia computing once the roadblocks to its implementation are removed, such as the excess of data 
required to represent a voice or video signal. The gap between multimedia developers and users is already narrowing with a new generation of multimedia authoring tools, including DOS- and Windows-based professional and business applications for use on $\mathrm{x} 86$ based microcomputers, Macintosh-based entertainment and education applications, and Unix workstation tools for engineering and professional applications (Cole, 1993).

The purpose of this project is to develop a Multimedia System that will help tourists who visit Miami International Airport to get all the necessary information. With the help of Audio and Video, tourists will get a real life view and voice explanation of all the facilities, other than the traditional plain information such as brochures, catalogs, planar view of buildings. And with the nature of GUI computer-human interface, the tourists can choose any section of video they feel interested to view instead of going along with the video tape programmed by the producer.

Hardware requirement: A 386 or better IBM-compatible PC with standard 16-bit ISA bus and Normal IDE hard drive and an Audio/Video compression/decompression board which will support 
both capture and playback of high-quality real-time video (30/25 frames per second NTSC/PAL video with a resolution of 320x240 by 16 color bits) in motion JPEG format (C-Cube Microsystems, 1992; Wallace, 1994), and $22 \mathrm{KHz}$ sampling frequency synchronized audio.

Software requirement: Include interactive programs that can help capture/digitize video and audio and save/load image formats such as TIFF, TARGA, PCX, BMP, YUV, IBM MMotion, etc. The utilities program also can play back video and synchronized audio. In spite of the utilities program, there are also function libraries for programming multimedia applications. Both function libraries and utilities program are available under DOS and MS-Window.

\section{Literature Review}

\subsection{The effectiveness of the audio/video multimedia technology in}

\section{computer-human interface.}

Because of the nature of human beings, the effectiveness of the multimedia systems in computer-human interface will be characterized by the following features: 
1. Since graphical user interfaces (GUIs) are more user-friendly, the visual characteristic of GUI is considered an essential element of multimedia technology (Bloor, 1993).

2. Benimoff (1993) suggests that media types, in addition to graphics, such as text, audio, video, and animation are likely to enhance computer/human interactive as well as interpersonal relationships.

3. Challengers in designing user interfaces of multimedia systems will evolve when considering some critical human factors and human natures (Bloor, 1993; Benimoff, 1993). Applications of the multimedia technology in telecommunications products and services, business, education, and home such as multimedia-based training, multimediabased performance support, business presentations, and multimedia conferencing will face the inevitable need specific to the multimedia design of computer/human interfaces (Benimoff, 1993; Sims, 1994; Donly, 1993; Lapante, 1993; Hwang, 1993).

\subsection{The application development of the multimedia technology in business application.}


The application of multimedia technology grows rapidly in business field nowadays(Donly, 1993).

The application of Market Intelligence Inc., a market research firm, report that the 1993 global revenue for both multimedia hardware and software will exceed 1992's level of $\$ 5$ billion by 45 percent, which is almost $\$ 7.2$ billion. The Global revenue for multimedia hardware and software in 1994 exceed 1993’s level by 49.7 percent, reaching $\$ 10.8$ billion. Computer Reseller News (CRN) and Gallup have conducted a poll in August 1993 regarding multimedia technology. The result shows that Fortune 1000 companies have been taking root by multimedia technology. About 40 percent of the companies indicate that they are using multimedia. There are 30 percent of the companies mentioning that multimedia technology will be brought into use within the next 12 months (Donly, 1993)

The implementation of new technologies differs between small and large business. For small business, the most common use of multimedia technology is to make more effective and attractive business presentations and for employee training (Lapante, 1993). Small 
business usually start their multimedia implementation from sound first instead of full-blown multimedia and will tend to delay the use of new technology when it is expensive (Lapante, 1993; Hwang, 1993).

For large corporations and government, they usually start their multimedia implementation from new technologies in order to get its business competition. The new technology not only get more effective and interactive business presentations for advertisers and clients but eventually reduces the expense for employee training in terms of cost and effectiveness (Hwang, 1993; Lapante, 1993).

\subsection{The development of the multimedia technology in education application}

The implementation of the multimedia technology in education application could greatly benefit students and classrooms. Through a touchwindow or a mouse, multimedia technology allows students to use computers to research more deeply in their interested academic area and conduct word search, note taking, and page marking. By offering different programs, multimedia system could also enrich and enhance 
the design of classroom functions and environment (Adam, 1993).

The development of the multimedia technology means especially

significant for students with special needs. Currently many school

facilities such as standard keyboards or writing instruments are

inaccessible to students without adaptive devices. Combined with

hypermedia, the vivid, lively multimedia classroom presentations may

greatly benefit students with learning disabilities, emotional problems, attention deficit disorders, mental handicaps and physical disabilities (Sim, 1994; Adam, 1993).

\subsection{The development of the multimedia technology in home}

\section{application}

It is evident that the use of multimedia technology is taking root in home applications (Donly, 1993). Many Windows-based multimedia CD-ROM provide a blend of text, sound, images, moving images and animation or full-motion sequences. For example, Microsoft Corp's Encarta is a multimedia CD-ROM encyclopedia with the above features (Waurzyniak, 1993). 
Multimedia technology blends technologies that are already in the market such as computer, radio and television. Without starting from scratch for the time-consuming research or experiments, multimedia technology could thus develop more rapidly than the other technologies. Moreover, since multimedia technology is a mixture of technologies which are already familiar to people, it will be very easy for anyone to assemble a multimedia system at home (Adam, 1993).

\subsection{Future trends of multimedia technology}

Owing to the decline of the worldwide economy, the costeffectiveness of a new technology will decide its market. That is, the higher the effectiveness, the lower the cost, the more popular the new technology may be.

Another challenge for the development of multimedia technology is the design of multimedia user interfaces by considering critical human factors. The emergence of multimedia technologies and their applications in telecommunications products and services (e.g. interactive TV services and Asynchronous Transfer Mode-ATM) might 
change the interaction pattern between human and systems (Bloor, 1993;

Benimoff, 1993; Rosenthal, 1993; Robichaux, 1993).

Storing and accessing continuous media (e.g., audio, video, animation, etc.) is a fundamental technology for all networked multimedia applications including video-on-demand (VOD), interactive TV (ITV), and interactive hypermedia courseware. Many organizations will want to store and manipulate video data. Because this volume of material cannot be stored economically on magnetic disks, tertiary storage will be used. The development of Video File Server (VFS), Archive Server (AS) using tertiary storage is very important for the future of multimedia applications. (VFS is an on-line cache for videos permanently stored on a tertiary storage archive server). (Lawrence A. Rowe and David A. Berger, 1996)

\section{Instrumentation}

\subsection{Hardware}

\subsubsection{JMC550 Board}

As computer been widely used in all kind of different environment 
in the current society, video signal processing has became more and more demanded. To store and transmit video signal require data compression technique. For example, with frame rate $25 \mathrm{fps}$ PAL format image, image size $768 \times 576$; use 24 bit data for true color, the data size for one second of video image is $31.6 \mathrm{MB}$. The data bus and storage device today still can not handle such a huge data transformation.

So data compression is the only way for video signal processing.

There are numerous video compression algorithms including:

Apple's Roadpizza, Supermac'sCINEPACK, Fractals, H.261, Intel's INDEO, motion JPEG (MJPEG), MPEG-1, MPEG-2, Sun's CELLB, and Wavelets.

Unfortunately, there is no single technology that can be used for all applications. For example, Apple's Roadpizza and Supermac's

CINEPACK are designed for playback applications with software-only decoding, H.261 is designed for video teleconferencing, MPEG-1 is designed for low bitrate (e.g., 1.5Mbs) audio and video playback applications, and MPEG-2 is designed for high bitrate, high quality playback applications with full-sized images (e.g., CCIR 601 with studio 
quality at 4-10 Mbits/sec).

Non-linear video editors are typically used in broadcast TV, commercial post production, and high-end corporate media departments. Low bitrate MPEG-1 quality is unacceptable to these customers, and it is difficult to edit video sequences that use inter-frame compression.

Consequently, non-linear editors (e.g., AVID, Matrox, FAST, etc.) will continue to use motion JPEG with low compression factors (e.g., 6:1 to 10:1).(Lawrence A. Rowe)

Motion JPEG compression has also been used in some desktop video conferencing applications (e.g., Insoft) because affordable workstation boards that support real-time encoding and decoding have been available. Typical boards cost $\$ 4 \mathrm{~K}$ to $\$ 10 \mathrm{~K}$. Motion JPEG boards are now being sold for PC's that cost $\$ 1 \mathrm{~K}$ to $\$ 4 \mathrm{~K}$.(Lawrence A. Rowe, 1995)

JMC-550 is a real time video compress/decompress video card. It can transfer PAL or NTSC TV signal to the hard drive in 25-30 frames per second with the images size of $320 \times 240$. It can also do real time playback in VGA display. JMC-550 use international standard JPEG 
compression method that can compress video data from 12 to 400 times with the average rate of $200-400 \mathrm{~KB} / \mathrm{sec}$ which make most computer be able to handle. A high-level block diagram of the add-on codec board is shown in figure 1. 


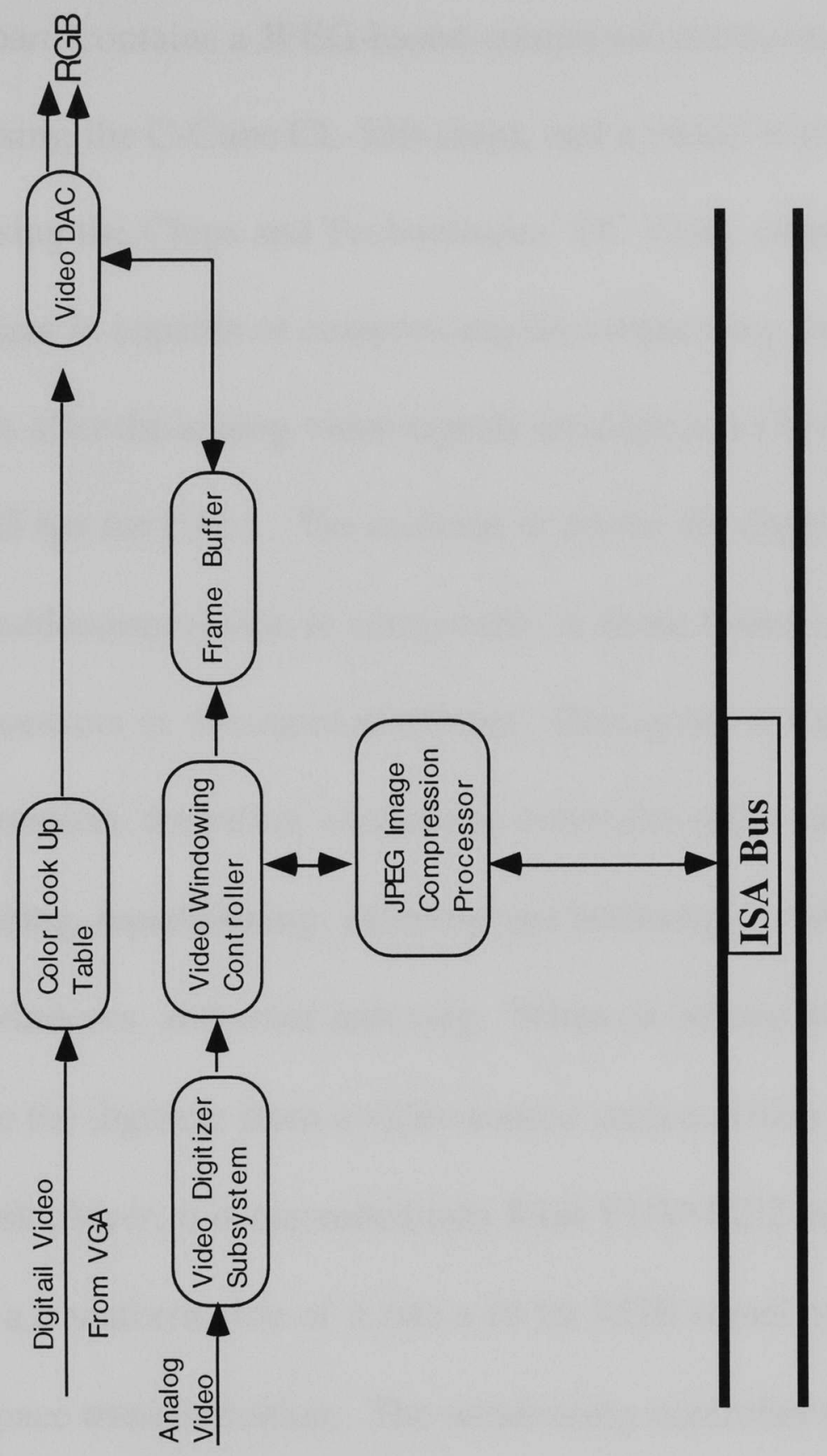

Figure 1. A Block Diagram of the Board 
The board contains a JPEG-based compression/decompression processor (using the C-Cube CL-550-chip), and a visual windowing controller (using the Chips and Technologies' PC Video chip). The codec processor is capable of compressing/decompressing the real-time video signals after the analog video signals are digitized (30 fps for NTSC and 25 fps for PAL). The realtime or on-the-fly digitizing and compressions/decompression is comparable to those found in high-end graphics processors or advanced platforms. During the compression and decompression, the visual windowing controller takes care of window resizing, repositioning, chipping and buffering, creation and deletion of windows, and color indexing. When an analog video signal is supplied to the digitizer from a video source such as video camera or VCR/laserdisk player, it is converted into 8-bit YUV 4:2:2 signal, followed by a transformation of it into a 16 bit RGB signal by the luminance space transformation. The windowing controller then scales, clips and positions the RGB signal and stores them in the frame buffer, where it is mixed with the digital signal from the VGA adaptor (which is converted into 16 bit RGB signal via a color look up table). The digital 
VGA signal is taken from the feature connector of a VGA/SVGA adaptor by a 25 pin digital cable. Finally, the mixed signal is sent out to the VGA/SVGA monitor after the digital/analog conversion to display. During the compression and digitizing (store the video in a file), the 16bit RGB video signal is sent to the bus via the 16-bit video DMA. The decompression process just reserves the above procedure. One of the major advantages using JPEG is that the compression and decompression that involves the DCT (Discrete Cosine Transform) are symmetric.

Analog audio signal is separately converted into a 8 bit digital signal by $22 \mathrm{KHz}$ sampling, and stored in the disk (IDE or SCSI) via the audio DMA. During its playback, the audio is converted back into analog signals and output to speakers, which is synchronized with the corresponding video.

Audio and video are stored in separate files, and there is a third file for synchronization. Marks (the corresponding video frame boundaries) are placed in audio file to indicate at which frame the audio should be played for the purpose of synchronization. After a video frame has been 
decompressed, audio will be compared with the video frame. If the audio lags behind the video, the current video frame will not be updated to hold on for one more frame. If the video lags behind the audio, then one frame will be skipped. The separation of audio and video makes it possible to support multilingual feature for voices by just attaching/linking different audio file to the same video file. Automatic synchronization of audio and video files is one of salient features of this board.

\subsubsection{Installing JMC550 board to an IBM Compatible PC.}

The PC with $50 \mathrm{Mhz} 486$ with $8 \mathrm{MB}$ of RAM and $200 \mathrm{MB}$ IDE hard drive is used for this project. The motherboard has only ISA buses with one Hard Disk and Floppy Drive controller, and one 8 bits graphic adaptor. The JMC550 board is installed into this PC's ISA slot and use feature connector cable to connect the graphic board as shown in Figure 2.

The connectors on JMC-550, shown in Figure. 3. First connect the VGA display to the VIDEO OUT port on the card, then connect 
audio and video output signal from VCR or Laser Disc to AUDIO and VIDEO INPUT ports, and plug the speaker cable into AUDIO OUTPUT port. The video output impedance is $75 \mathrm{~Hz}$, matching the VGA standard; the audio output impedance is about $50 \mathrm{mV}$ and is compatible with the amplifier and VCR.

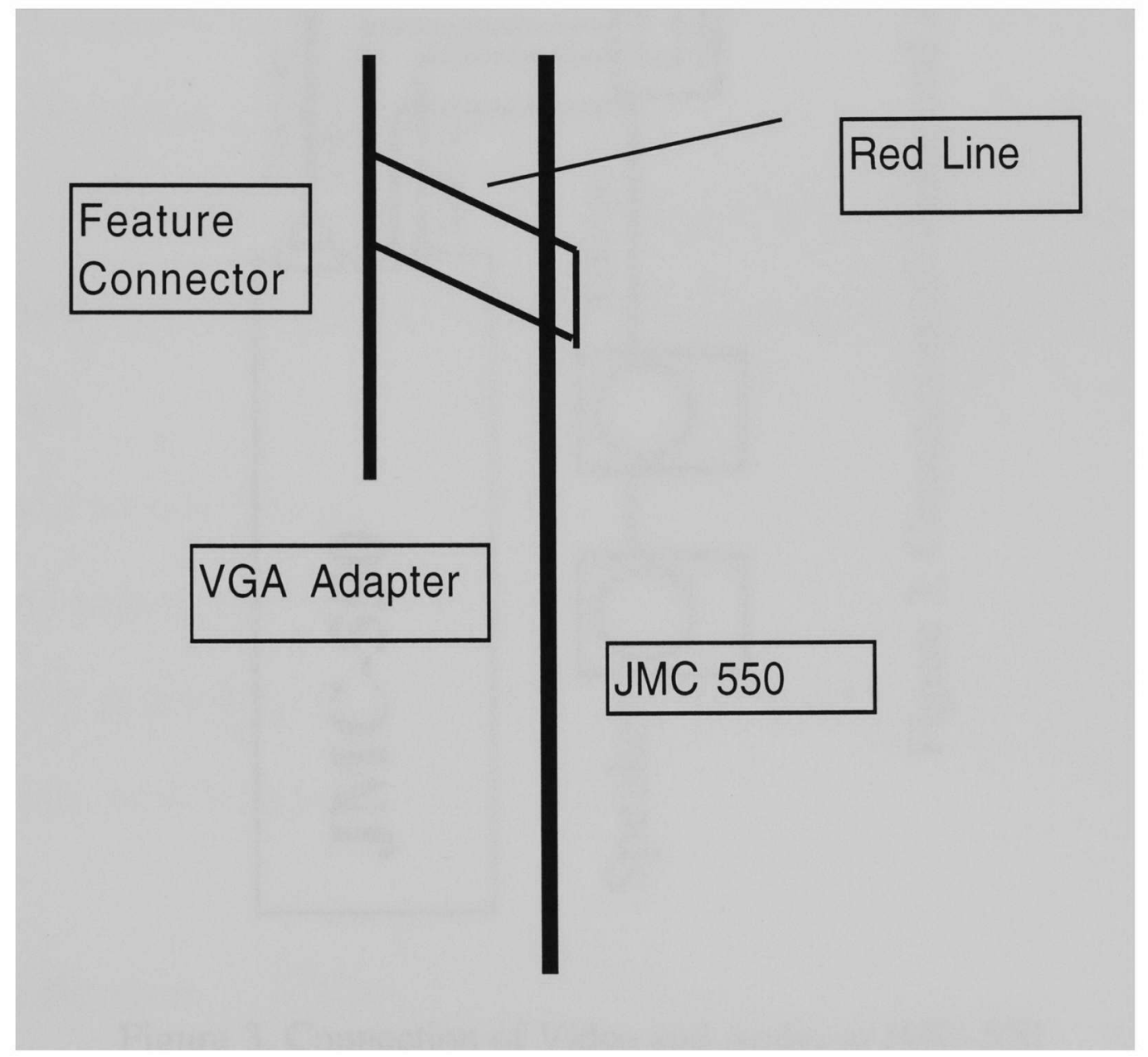

Figure 2. The connection between VGA adapter and JMC550 


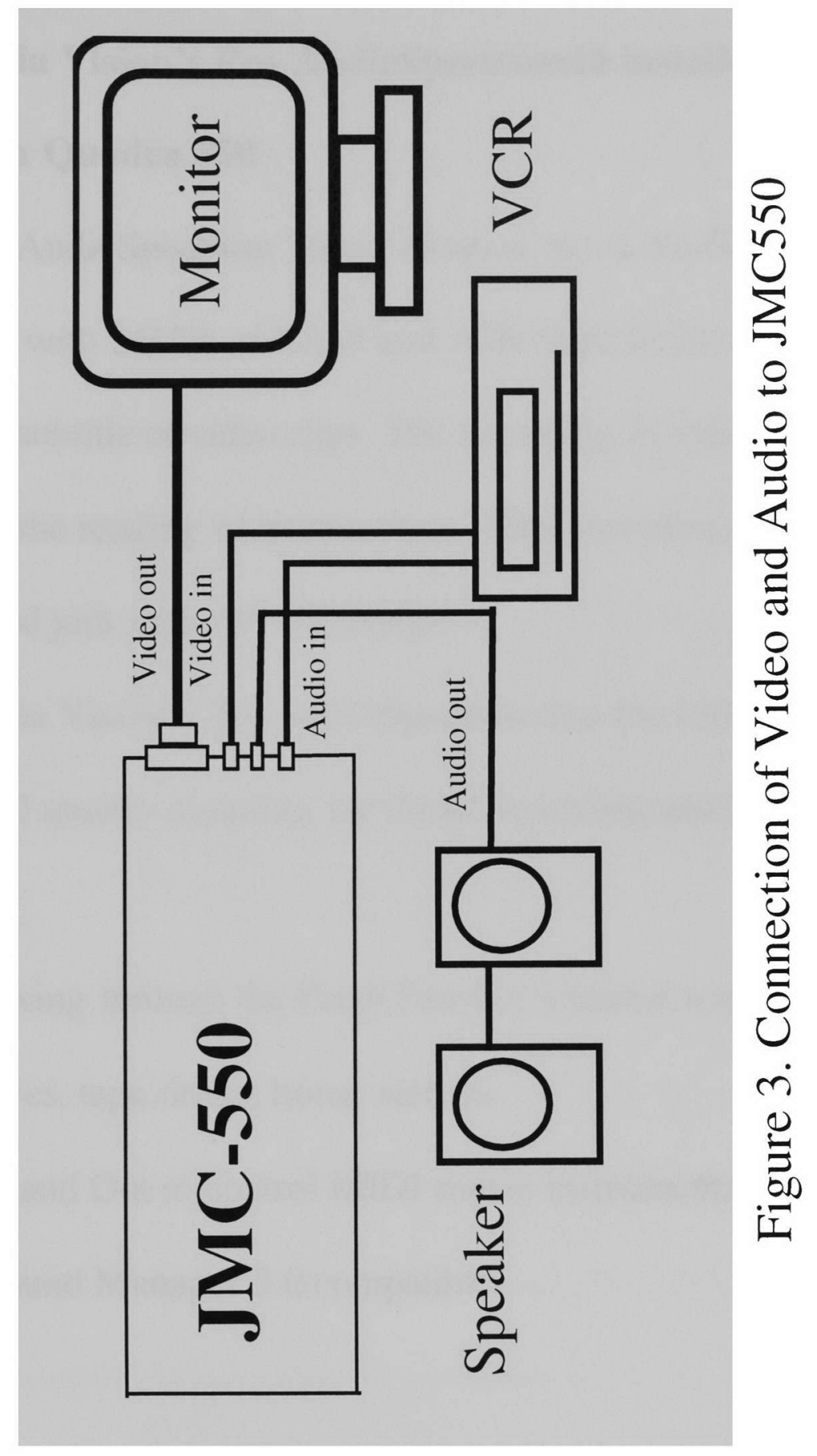

Figure 3. Connection of Video and Audio to JMC-550 


\subsubsection{Media Vision's Pro AudioSpectrum16 installed in a}

\section{Macintosh Quadra 800}

The AudioSpectrum 16 are installed into a Nu-Bus base

Macintosh with 24MB of RAM and 1GB Hard Drive. It is used to

record the subtitle of video clips. The recording include background

music and the reading of manuscripts. After recording, they are mixed together and join with the video clips.

Media Vision's Pro AudioSpectrum has the following features:

- 16-bit CD quality sampling for digital recording and playback of sounds.

-Audio mixing through the Patch Panel of external sources from CDROM Drives, tape decks, home stereos.

- MIDI In and Out to control MIDI music instruments.

- Apple Sound Manager 3.0 compatible.

\subsection{Software}

\subsubsection{JMC-550 software package}

The JMC-550 software packages consist of the following 
components:

- Multimedia control (dynamic and static) function libraries under MS-Windows and DOS

The system software libraries have two versions: a dynamic linking library (DLL) for MS-Windows, and a static linking library for MS-DOS, which provide real-time video compression/decompression and visual windowing functions. These libraries are compatible with Borland $\mathrm{C}, \mathrm{C}++$ and MicroSoft Visual $\mathrm{C}++$.

- Multimedia control utility programs under MS-Windows and DOS

The interactive utility programs support interactive manipulation of multimedia data such as editing video/audio clips by cut/paste/copy, selecting input video mode (NTSC or PAL), freezing/saving/loading a frame in different formats, digitizing and playing back a video via a VCR-like control panel, adjusting compression ratio, frame rate, and color etc.

- MDK Authoring Tool kits under MS-Windows.

MDK Authoring Tool kits provide a simple way to link and 
organize window frames, buttons, background pictures. It is composed of editor, interpreter, librarian, system configure program and help system. The editor can be used to define the attributes of each window, linking windows in a tree structure, using buttons to pass the control between windows, providing interface and control for JMC550 video/audio files, importing bitmap picture and buttons to make the user interface looks better. The interpreter is to run the script generated by the editor. The librarian manager text, icons, bitmap images, buttons and video files can be used by the editor and the interpreter. The system configure program is to configure MDK editor and interpreter to match the hardware setting of the system. The help system is available in all programs described above and can be called at any time during the execution.

\subsubsection{SoundEdit Pro}

SoundEdit Pro is a powerful software package produced by MacroMedia can be used on a Macintosh family of computers. It can edit, enhance, play, analyze and store sounds. By using effects such as echo, reverb, normalize, and pitch shift, we can alter the tracks to our 
liking. Each track contains separate level and pan controls for changing the volume of the sound as well as its position in the stereo field (left, right, or middle). These separate tracks can be combined into a single track or stereo pair with the Mix command.

\section{Multimedia application design using MDK authoring tools}

These section is compose of two subsections:

1. Producing a Multimedia Application using MDK authoring tools.

2. MDK system modules

\subsection{Producing a Multimedia Application using MDK authoring tools.}

These are steps to produce a multimedia application:

1. System design

2. Recording of the messages

3. Editing

4. Maintenance

All these steps will be discuss in more detail in the following section. 


\subsubsection{System design}

System design is composed of three parts:

- System structure

- Hardware requirement

- Content preparation .

- System structure

The first step of system design is to determine the goal of the system, the functionalities of the system and the interface of the system.

Screen is the basic unit of MDK multimedia system, a system is composed of several screens. MDK use button to link screens together. Text, button, image, frame and video are attributes of a screen.

System structure is like a tree structure that compose of screens and link by buttons. For example: a hotel multimedia systems' structure

1. Introduction

2. Rooms

3. Entertainment
1.1 Facilities Overview

1.2 Facilities Directory

2.1 Standard Room

2.2 Deluxe Room

3.1 Night Club 


\subsection{Fitting Center}

4. Dining

\subsection{Restaurant}

\subsection{Fast Food}

After complete the system structure design, we can start to design each screen. Each screen may compose of following attributes:

- Background image

- Buttons

- Information images

- Text

- Video or Animation

For example, the main screen of the previous hotel multimedia application may look like this figure 4 . 


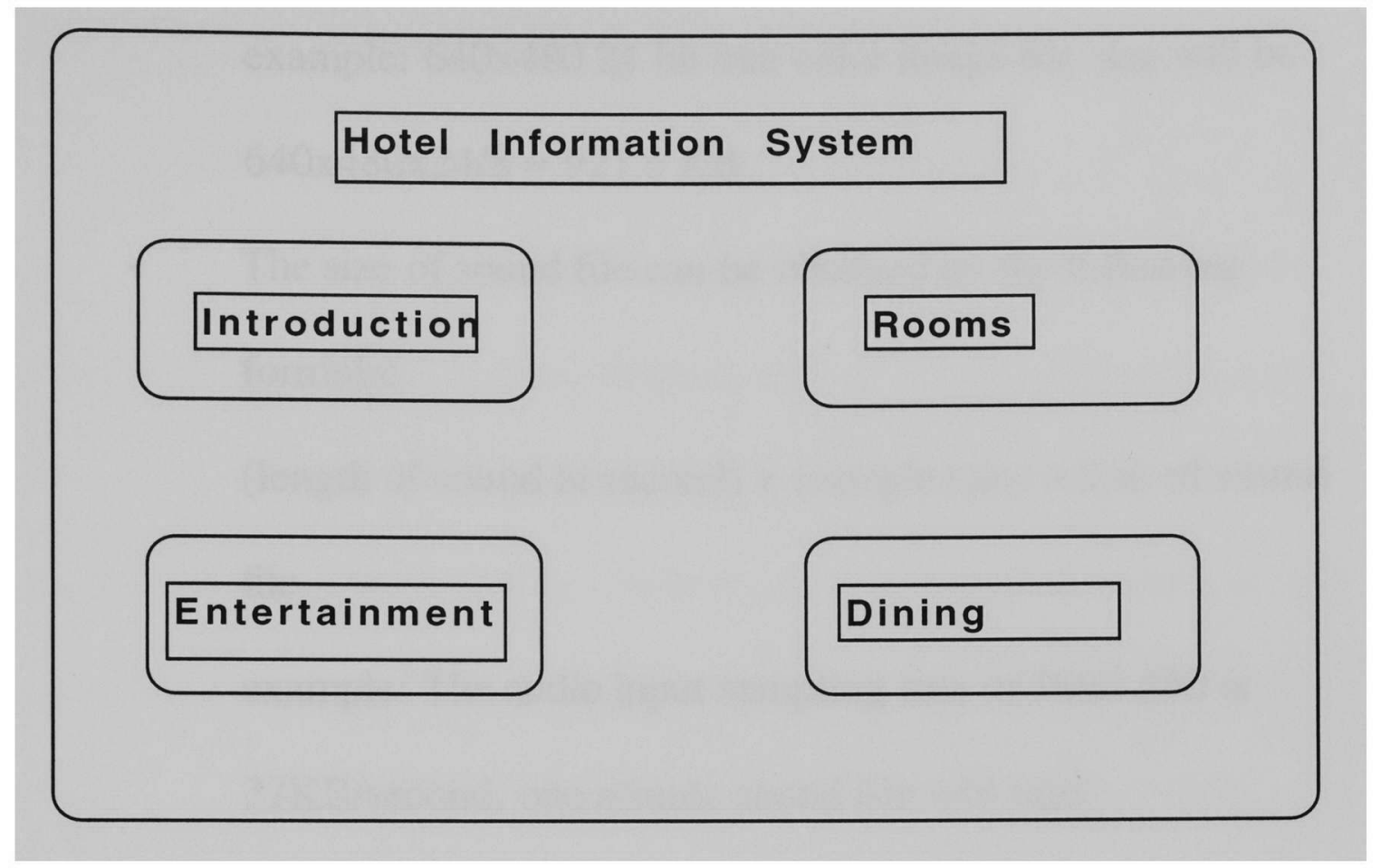

Figure 4. The main screen of the hotel multimedia application

- Screen Name: Main Screen

- Background image: Outside view of the hotel

- Hardware requirement

Estimate hard disk space requirement for multimedia project.

- $\quad$ MS-DOS, MS-Window, MDK take about 30 MB

- $\quad$ The size of images file can be obtained by the following formula:

length $\mathrm{x}$ width $\mathrm{x}$ (color depth) $/ 8=$ file size in $\mathrm{KB}$ 
example: 640x480 24 bit true color image file size will be :

$640 \times 480 \times 24 / 8=921.6 \mathrm{~KB}$

- $\quad$ The size of sound file can be obtained by the following formula:

(length of sound in second) $\mathrm{x}$ (sample rate) $=$ size of sound file

example: The audio input sampling rate of JMC-550 is $22 \mathrm{~KB} / \mathrm{second}$, one minute sound file will take:

$60 \times 22=1.32 \mathrm{MB}$

- $\quad$ The size of midi sound file is very small.

- $\quad$ Video file: By choosing 50-70 for Q factor, JMC-550 can compress video file with $100-150$ to 1 ratio, one minute video file will require about $12 \mathrm{MB}$.

- Content preparation

After considering all the above factors, we should also reserve hard drive space for further expansion flexibility. Develop a multimedia system involved in the following task:

Prepare content of a multimedia system in following format: 
- $\quad$ Text: Writing messages.

- Image: create image using appropriate tools.

- $\quad$ Picture: capture video frame or scan photograph. Usually picture file need to be processed by image processing tool like Adobe Photoshop.

- $\quad$ Sound: recording explanation script, background music and synthesize sound effect if necessary.

- Video: Using JMC-550 digitize video source into hard drive. May require movie production, which includes writing a scenario, photographing, synchronizing the sound track of a film with the scenes.

After all necessary information is ready, recording all the messages into hard drive, then use MDK to integrate the system.

\subsubsection{Recording of the messages}

Messages type includes text, image, audio, animation and video.

To generate all the messages a multimedia application needs may require to compose or translate an article, draw images, record audio and video source. After all the messages required are generated, they will be put 
into the library. Here are suggestion in how to record different type of information into hard drive.

Text: we can use any word processor to edit the text contain, or we can directly edit the text within database tool.

Image: The image MDK use is in windows bitmap format. We will need some image tool like Paint Brush from window to draw the image we need. We can also convert image from other format by using image conversion utilities. There are CD-ROM titles that collect images of differ topics or we can download images from the Internet, but we have to honor the copyright of the images. Also, capturing image from the still frame of video files is another image source, but you will need to save the file as 24 bit BMP. Usually, we will need some image processing tools like Adobe Photoshop to post process the image so that they can show special effects or make the image more clear.

Audio: we can get audio by record sounds using sound blaster card or use MIDI interface to record MIDI sound file. We can use window media player or JMC-video with Microsoft Video for Window to edit the sound files. 
Video: JMC-550's video tool is ideal for input video data from VCR tape or video recorder, after doing so, JMC-550 video tool is also good in editing video data. We can cut each single frame or a section of video and insert them anywhere we want them to be by just using JMC550 video tool.

MDK provide different buttons that can be used to link between screens, if we need new buttons, we can use drawing tool like Paint Brush to draw new buttons, a button need two images, one image to show the button that are not been pressed, one to show the button that been pressed down. Usually the pressed down button is a shift of the original button to the right-down direction. We can also have invisible irregular shape of buttons to be used for clickable maps. After the buttons are made, they need to be placed under the BUTTONS directory under MDK directory.

All the information will need to be put into the library, we will discuss that later.

\subsubsection{Editing}

Make use of the MDK's WYSIWYG editor according to the 
system structure design.

After all the messages been put into the libraries, we can start using MDK to edit the system according to the system design. The editor provide a user friendly graphical interface which is WYSIWYG. We will construct the system using screens and link screens using bottoms. The attributes of a screen can be added to the screen by using the Tool Box. The buttons, images, text, frame and video can be selected from the Tool Box and then added to different screens. There will be a structure window that let us view the hierarchy structure the system and also a simulate mode to view the result of the system.

Because all the information are store in the libraries and are referenced by their names, the update of the information does not require the change of the overall system structure.

\subsubsection{Maintenance}

Maintenance a multimedia application include renewal of the messages, change the system structure according to the needs and the nature of the new messages. 


\subsection{MDK system modules}

\subsubsection{Libraries Management}

All the information that MDK can use must store in the database libraries. These are the libraries MDK provide:
- Button library
- Text library
- Image library
- Audio library
- Video library

\subsubsection{Main Menu}

The library management tool has the following main menu items:

- Browse: list all the records. The records are editable when listed.

- Edit: edit the record chosen.

- Help: Library help system.

After choose Edit or Browse menu, three menus appear:

\section{- Edit Menu}

Add blank: Add an empty record at the end of the library Add copy: Add an copy of selected record to the end of the library 
Delete: Mark the selected record deleted.

Undelete: Delete mark of the deletion for a record.

Pack: Actually delete the record that been marked deleted.

\section{- Location menu:}

Find: Find the name of a record.

Bottom: go to the bottom of the library.

Top: Go to the top of the library.

Go To: Go to the numbered record.

\section{- Index Menu:}

Reindex: Re-indexing the library

Select: select the index method: by name or record number.

\subsubsection{Tools bar}

The following are tools listed in tool bar.

- Text editing button: Only can be use when editing text library.

It will pop up a window to edit or change text content.

- Device Type: Only can be used in image library and video

library. To change the device type of supported device listed.

- Save: Save change into hard drive. 
- Find: Find item in the index list.

- Go to top: Go to the top of index list.

- Go to bottom: Go to the bottom of index list.

- Color: Only can be use in button library and image library, change the color or make image transparent.

\subsubsection{Button library}

Name: The name of the button must be unique.

Normal: The name of the image when a button has not been press down.

Selected: The name of the image when a button been pressed down.

Tnsp: Transparent button

All the button image files must be in the button directory, the library only keep a copy of the index but not the actual image file.

The image for button support BMP, PCX, TIF, GIF, CUT, TGA, JPG PCT and RLE. The user interface for button library is shown as Figure 5 


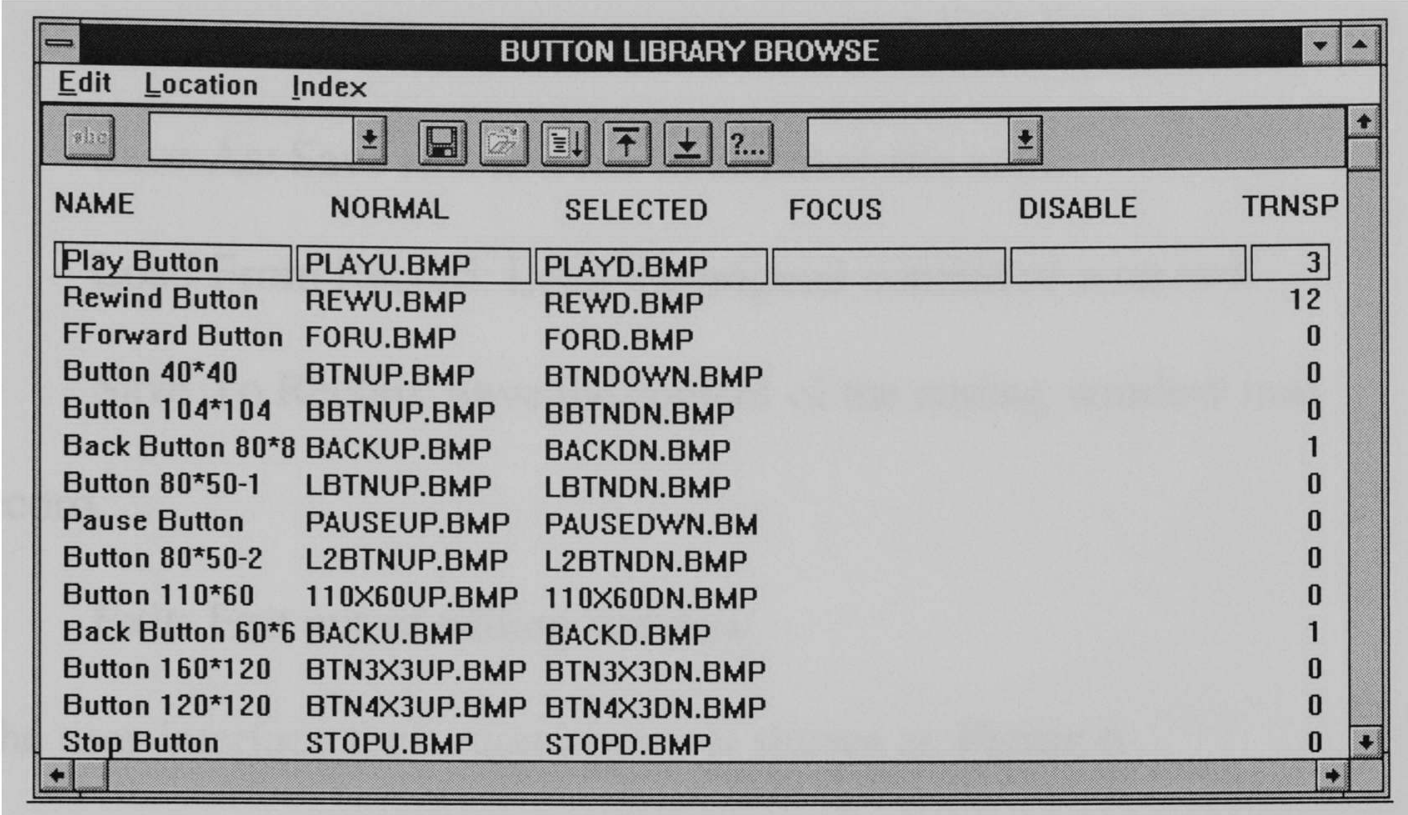

Figure 5. Button library browse

\subsubsection{Literal Library}

Each text item contain the following:

Name: unique name

Text: The content.

To create a text item, first create a blank record by Add Blank

menu item, then enter the unique name for that record. After choose edit, the edit window will popup (Figure 7).

New: Create new item.

Open: Open a text file. 
Save: Save as a text file.

Save As: Save as a text file in different file name.

Load From Record: Load the original content of a record.

Save To Record: Save the content of the editing window into record.

Exit: Exit out of editing window.

The user interface for button library is shown as Figure 6

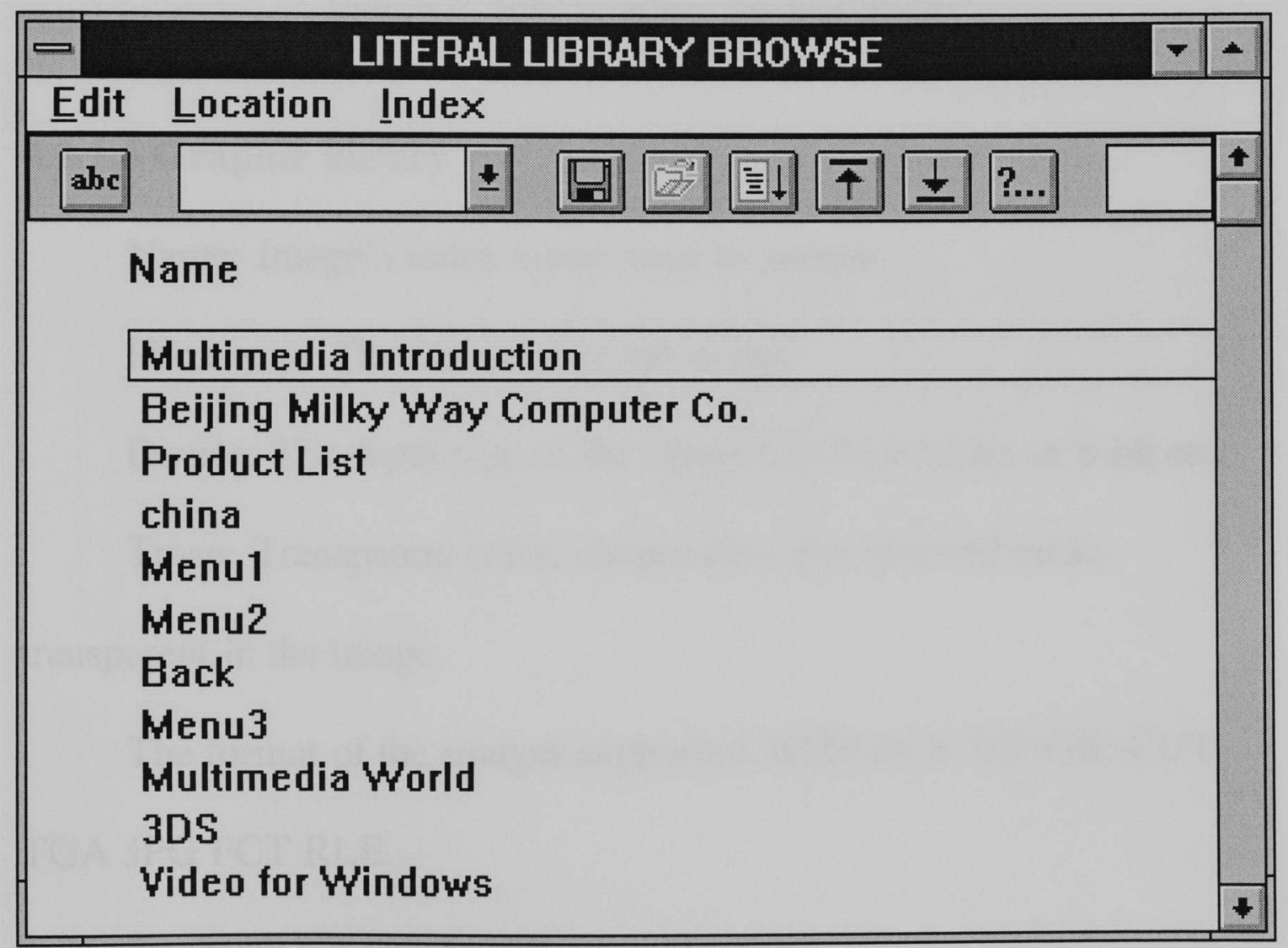

Figure 6. Literal library Browse 


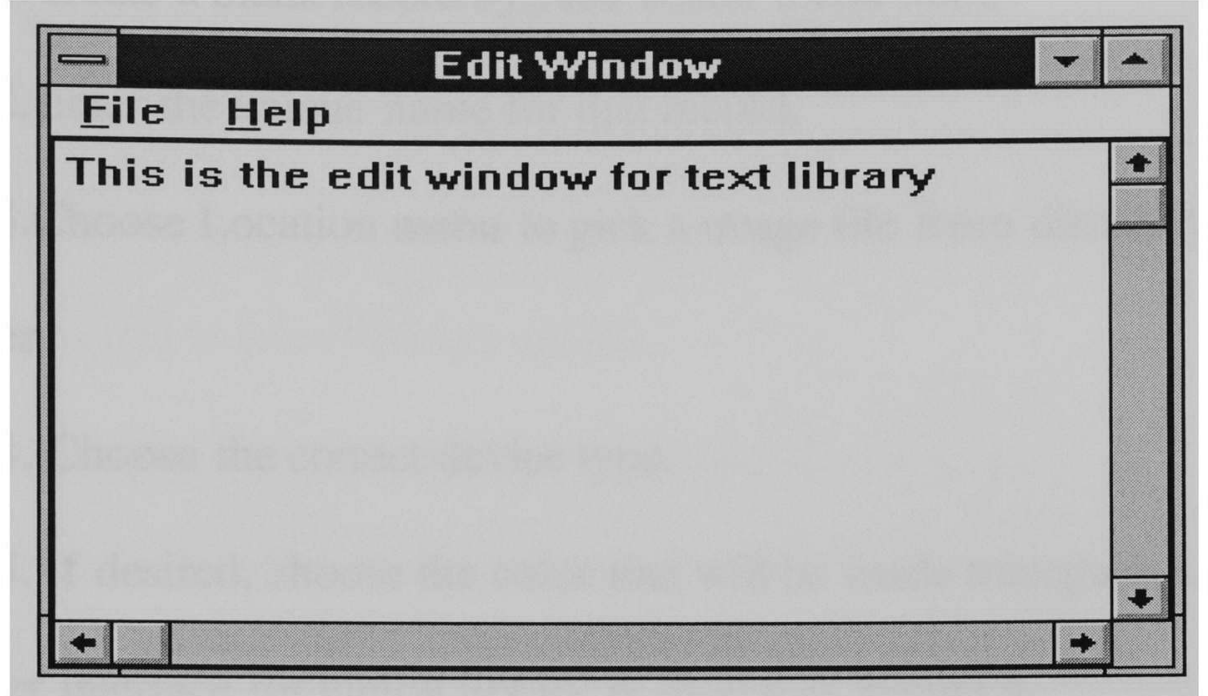

Figure 7. Edit window for text library

\subsubsection{Graphic library}

Name: Image's index name must be unique.

File Name: The file name of the image.

Device: The depth type of the image like True Color or 8-bit etc.

Trnsp: Transparent color, choose the color that will make

transparent in the image.

The format of the images supported: BMP PCX TIF GIF CUT

TGA JPG PCT RLE.

To create a image record, 
1. create a blank record by Add Blank menu item,

2. enter the unique name for that record.

3.Choose Location menu to pick a image file from directory

browser.

4. Choose the correct device type.

5. If desired, choose the color that will be made transparent.

The user interface for button library is shown as Figure 8.

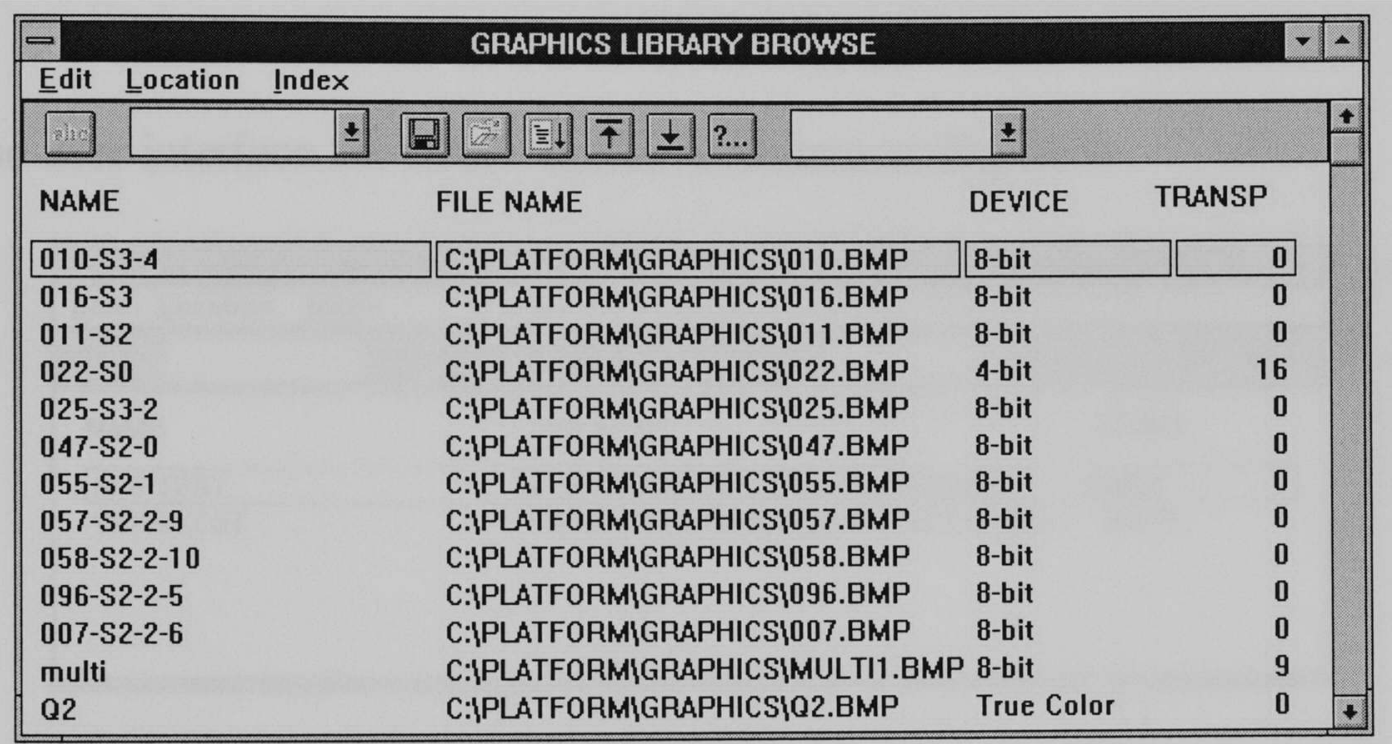

Figure 8. Graphic library browse

\subsubsection{Sound Library}

Name: Unique name of sound library index. 
File Name: File name of the sound file

Device: Choose the format of the sound file, like WAVE or MIDI

etc.

To create a sound library record,

1. Create a blank record by Add Blank menu item,

2. enter the unique name for that record.

3.Choose Location menu to pick a image file from directory

4. Choose the correct format in "DEVICE" field.

The user interface for button library is shown as Figure 9

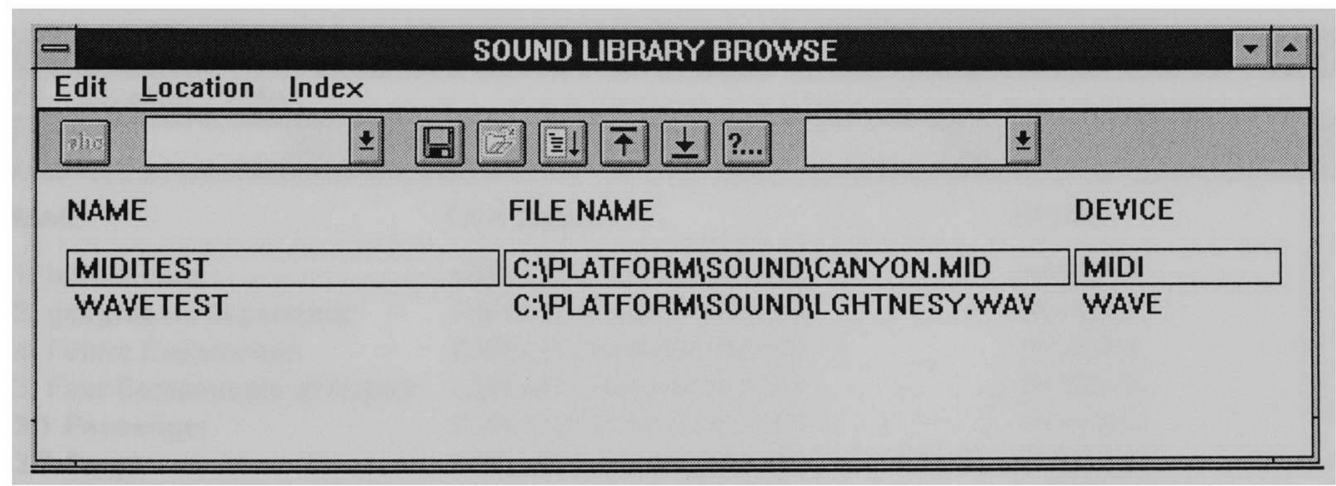

Figure 9. Sound library browse

\subsubsection{Video Library}

Name: unique name for video record. 
File Name: File name for video file.

Device: The format of video file like JMC-550, 3DS or AVI.

To create a video library record,

1. Create a blank record by Add Blank menu item,

2. enter the unique name for that record.

3. Choose Location menu to pick a image file from directory If the file is in JMC-550 format, use .VID for file name extension.

4. Choose the correct format in "DEVICE" field.

The user interface for button library is shown as Figure 10.

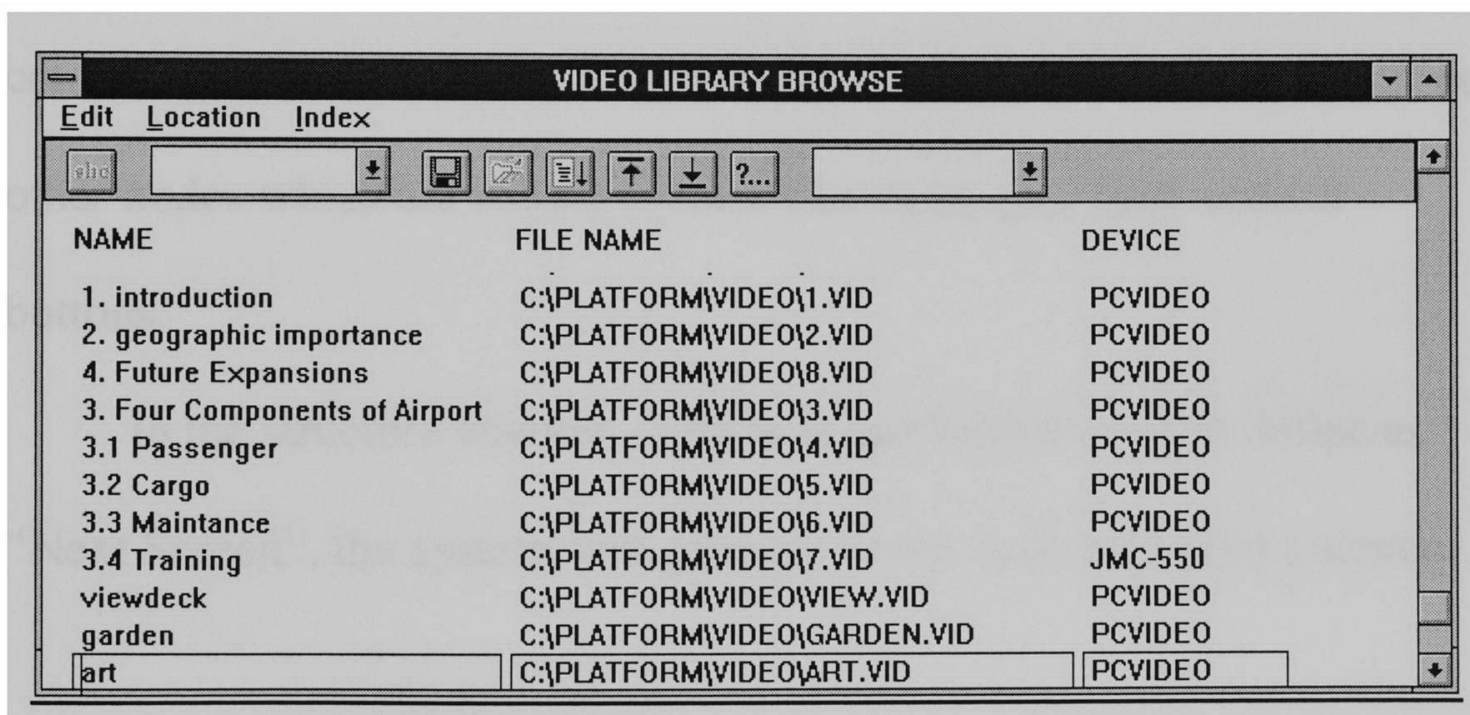

Figure 10. Video library browse

\subsubsection{MDK Editor}


MDK editor includes structure window and edit window, structure window is to display the logical structure of the application and the edit window is to modify/view the screen layout.

\subsubsection{Structure window}

Figure 11 is the structure window for MDK editor, it represent the structure of this project. Node $\mathrm{S}$ in figure 11 is the root node, node $\mathrm{S} \_3$ is a bottom which will lead to a screen include node S_3_4 and node S_3_3, node $\mathrm{S} \_3$ _4 is also a button, but this one will lead to a screen includes one background bitmap picture node $S \_3 \_4 \_8$, one video control node S_3_4_3, one JMC video/audio clip node S_3_4_2 and six other nodes which are control buttons like video play back control buttons.

In the structure window, if there is any button's action define as "Next Screen", the system will generate a new node represent a screen. 


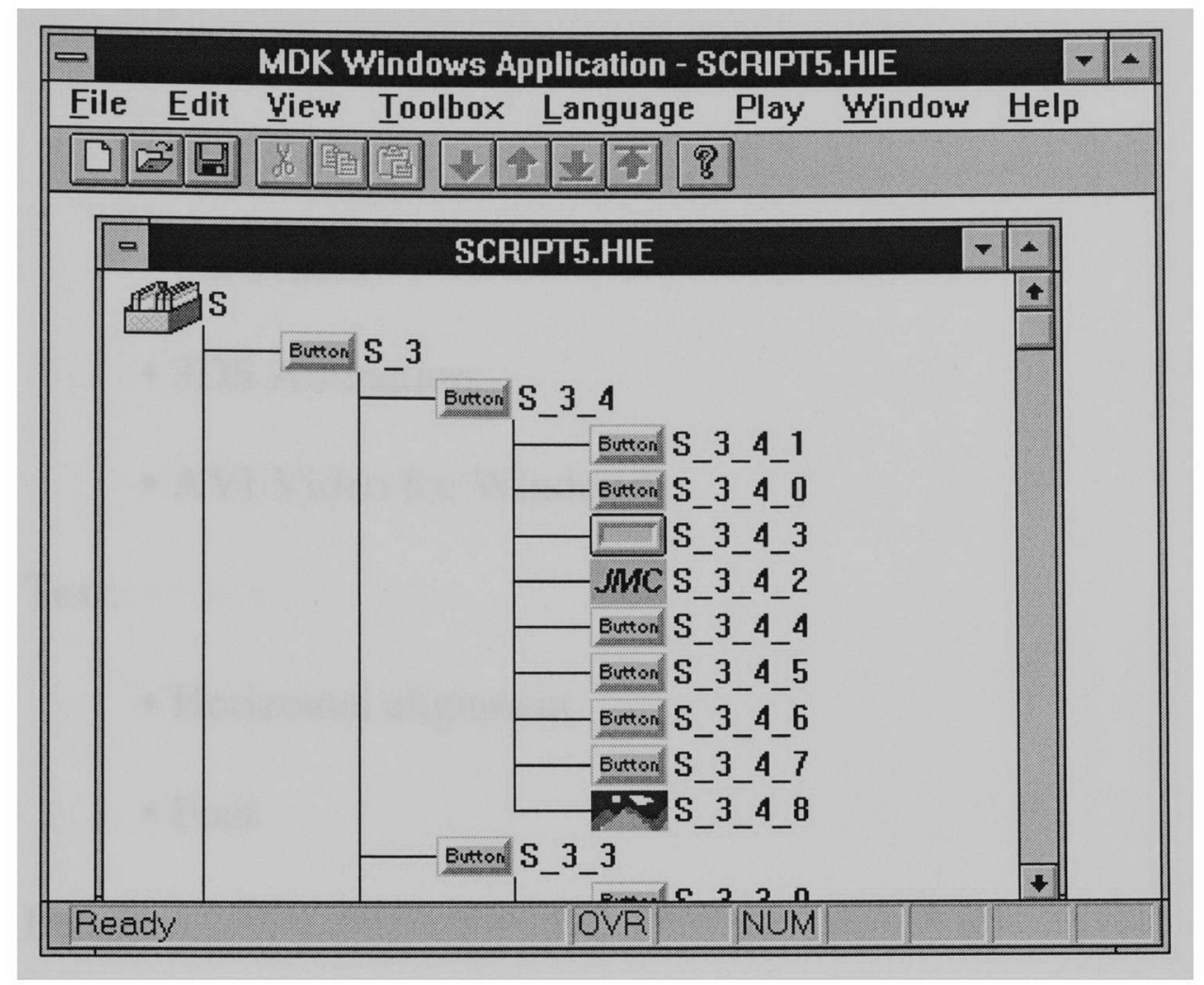

Figure 11. MDK Structure Window

\subsubsection{MDK Tool box}

With MDK tool box, we can assign different attribute to different elements: button, text, images, audio and JMC-550.

Button:

- Screen

- PC Video Window:

- System: 
- Wave:

- Midi:

- CD Audio

-3DS Animation:

- AVI Video for Windows

Text:

- Horizontal alignment

- Font

Image:

- Display method

- Fill in Full Screen

- Use owned palette

- Output Style

JMC-550:

- Contents

- Load Graphics

- Play Sound

- Play Video 
- Size

- Standard Size

- Full Screen

Panel Class Name:

- Style

- Color

- Text

\section{Design and Implementation}

\subsection{Design}

This project is to present a multimedia system base on low-cost IBM-compatible PC,JMC-550, MDK multimedia tool kits and is designed for Miami International Airport as a tourist guide for passengers and to demonstrate the functionalities and facilities of the airport.

In order to provide tourists basic information about Miami International Airport, the following components of Miami International Airport are presented in the design: Facilities Overview, Passenger 
Services, Cargo Services, Maintenance and Training Facilities etc. In addition, the directories for different services to help passenger locate the correct spot they need to go are also included.

The structure of the system is like a file directory tree structure (Figure 12), the user will travel through the system by following the path of the tree, in addition to that, each screen has a special button that will take the user right back to the top level of the tree for faster access. Buttons on each screen are the doorway to different parts of the system, by using a touch screen, one simple touch on the screen will lead the user to the path they choose. Some nodes of the tree that labeled (Video/Audio) has information in Audio/Video format in which make use of JMC-550's functionalities, others content bitmap image that provide graphic information for that area.

Every screen has a bitmap image. Some screen's images are used for background, and the others are for information purposes. Buttons are placed on the top of the image. All screens except the main screen will have at least two control buttons: one is to take the user back up one level, and the other is to take the user back to the main screen. 


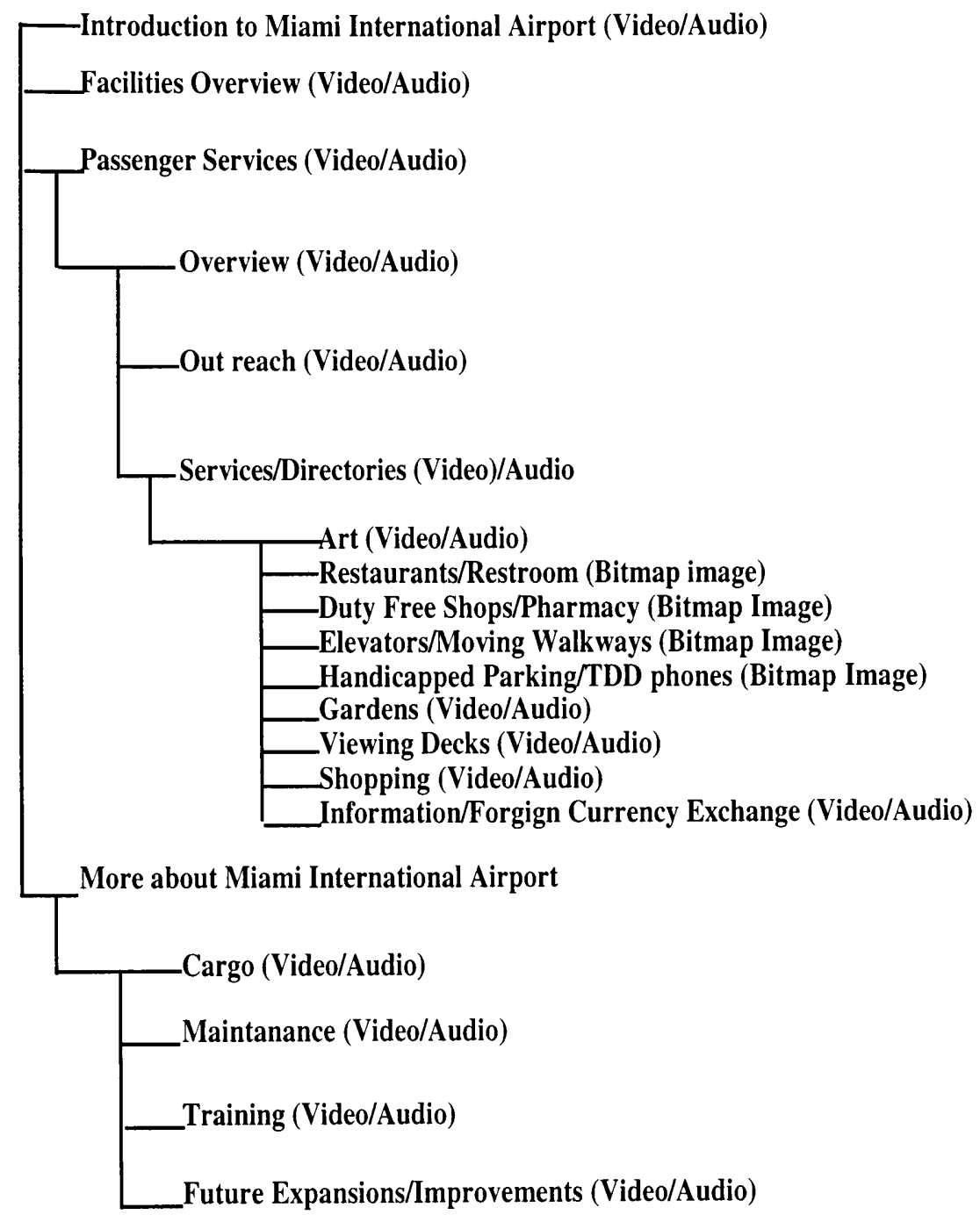

Figure 12. Structure Diagram of Introduction to MIA

Most screens with video data will have five control buttons for the video: Play, Fast Forward, Fast Rewind, Stop and Pause. The video screen are positioned above these control buttons.

The main screen (Figure 13) is composed of four buttons and a 
background image.

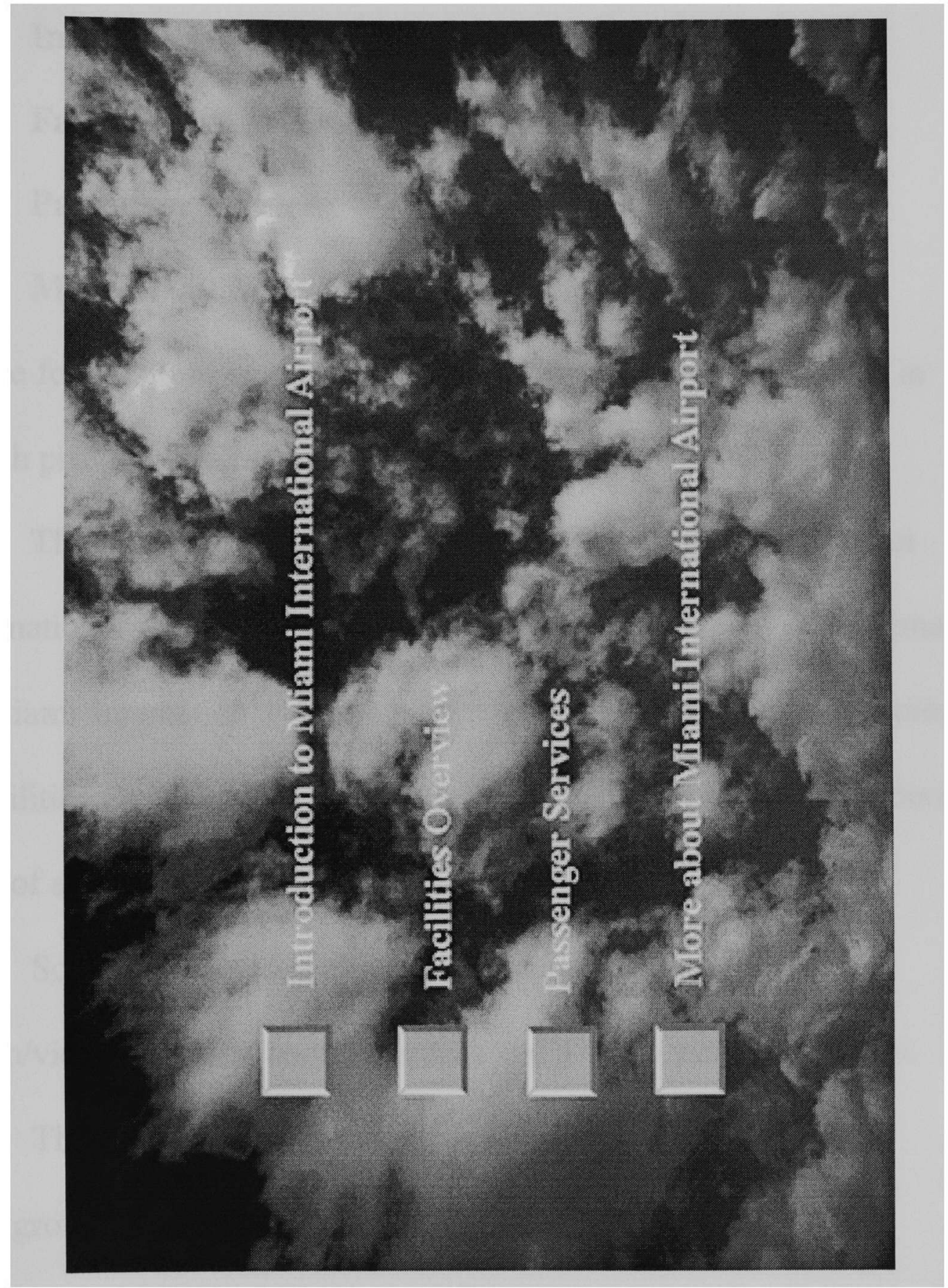

Figure 13. Main Screen of this application 
These four buttons are :

\section{Introduction to Miami international Airport}

\section{Facilities Overview.}

\section{Passenger Services.}

\section{More about Miami International Airport.}

These four buttons lead the user into different path of the system in which provide different information.

The first bottom of the main screen: "Introduction to Miami International Airport" is a video clips which gives a general information of Miami International Airport. The second button of the main screen: "Facilities Overview" is also a video clips that give the user a general idea of airport's facilities.

Screens with video clips are consist of background image, audio/video playback control buttons and a video playback screen.

The video playback screen is placed in the center of the background screen. 


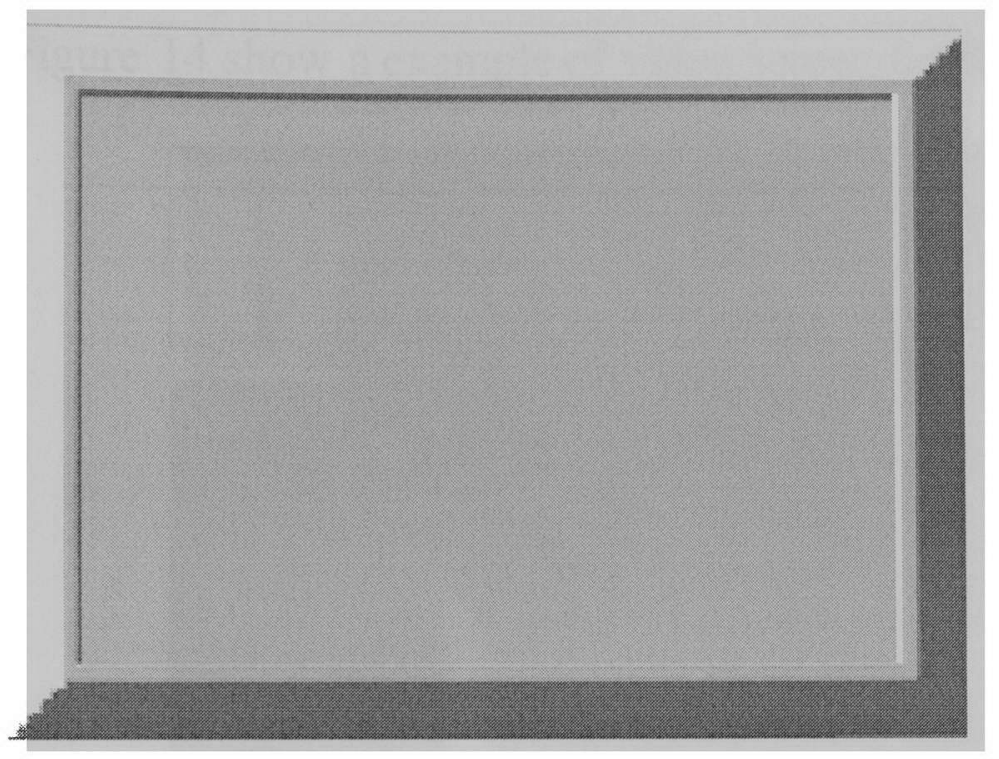

Video clips are play in the "high" are of the video playback screen.

At the bottom of the video screen are playback control buttons:

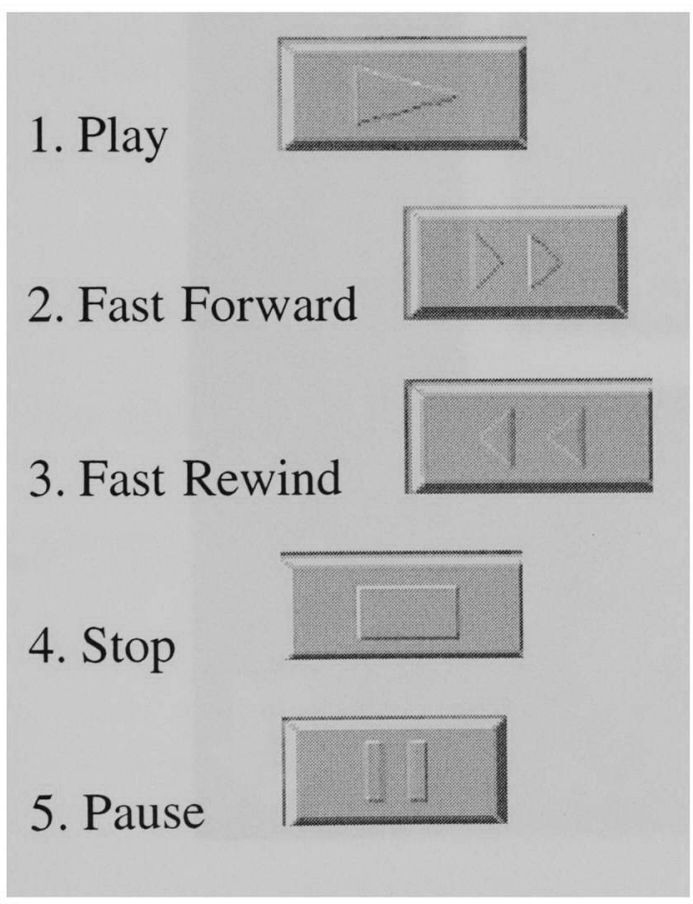


Figure 14 show a example of video screen for this system.

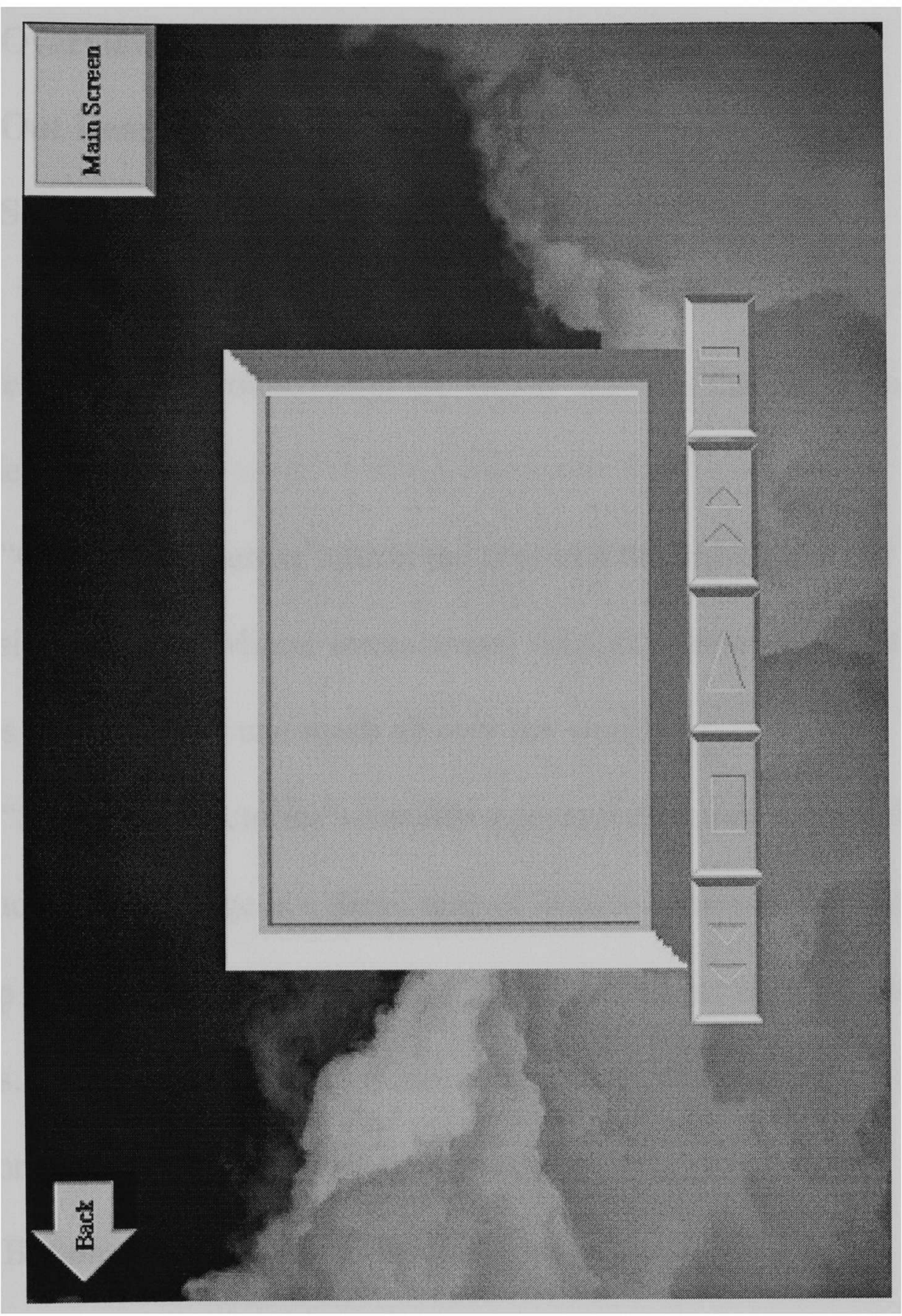

Figure 14. Video Screen 
The third button "Passenger Services" contains three buttons:

\section{Overview (Audio/Video)}

\section{Out Reach (Audio/Video)}

\section{Services/Directories. (Bitmap Image)}

The "Overview" button leads the user into a video section that provide a general introduction of the airport services that the airport provide.

"Out Reach" button inform the user that the dimension and expansion power of Miami International Airport is unlimited, that is, the airlines of this airport can reach all over the world.

"Services/Directories" contains a general directory for the airport. The background image is a detail map of Miami International Airport. On top of the map are nine buttons. These buttons are divided into two groups, one group which has video information and the other one has directories for different service facilities.

Buttons lead into video clips information:

\section{Art}

\section{Gardens}




\section{Viewing Decks}

\section{Shopping}

Buttons lead into bitmap images with directory information:

Restaurants/Restroom

Duty Free Shops/Pharmacy

Elevator/Moving Walkways

Handicapped Parking/TDD phones

\section{Information/Foreign currency exchange}

"Services/Directories" are shown as Figure 15 as an example of Bitmap Screen with buttons.

The fourth button "More about Miami International Airport" contains information about four areas of the airport:

\section{Cargo}

Maintenance

\section{Training}

\section{Future Expansions/Improvements.}

These buttons all lead to screen with video clips. "Cargo" contains video that pictures the cargo volume handled by the Miami 
International Airport which is the ranked number five in the world. The out reach range for the cargo handled by the airport has been throughout all over the world. The "Maintenance" part talks about user the maintenance facilities for different airlines in the airport. The "Training" part provides information about Miami International Airport that it is the largest "Training center for commercial airlines."

The final button "Future Expansions/Improvements" presents the expansion plan and the on going construction for the airport. 


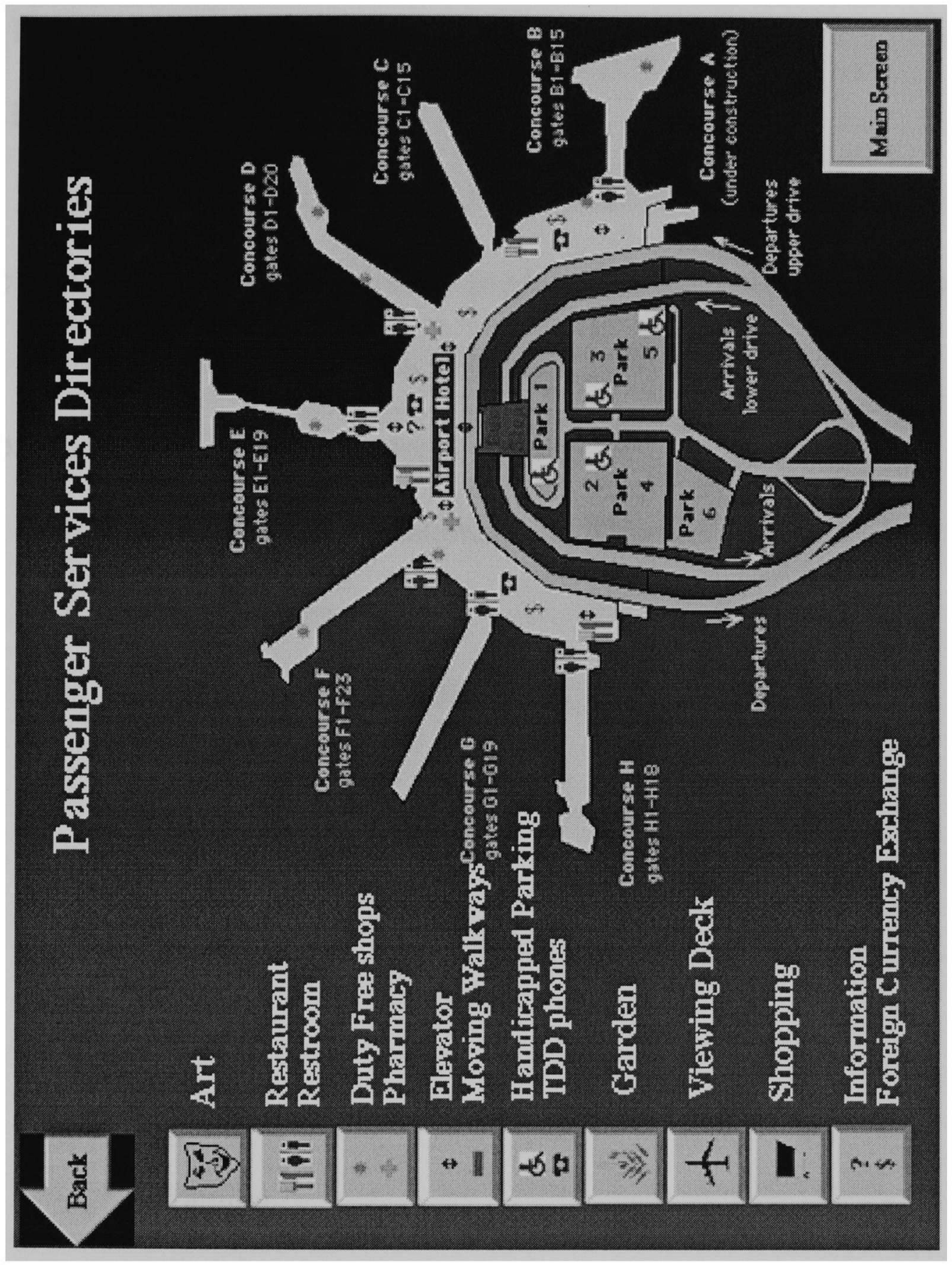

Figure 15. Bitmap Screen with buttons 


\subsection{Implementation}

\subsubsection{Video Clip Production}

The video clips for the following sections are coming from a video tape "Miami International Airport" produced by the Broadcast Quality Inc. with the permission of Office of Public Affairs, the Aviation Department of Miami International Airport.

- Introduction to Miami International Airport

- Facilities Overview

Subsections of "Passenger Services"

- Overview

- Out Reach

Subsections of "More about Miami International Airport"

- Cargo

- Maintenance

- Training

- Future Expansions/Improvements

The content of the video tape can be divided into different sections and each section has it's own independent topic. There are special 
effects with continued audio and video fade in and fade out between sections.

The video clips are played from a VCR with audio and video RCA line output connected to JMC-550's audio and video input jack respectively. Using the playback/recording tool provided by JMC-550's software package, each video clip are digitized and recorded into the hard drive of the computer. To accurately generate the video clips for each section, I have to cut the audio and video data between sections. To achieve this goal, each clip is recorded a few seconds before the section and lasts a few seconds longer after the section. hen The video clip is cut frame by frame till the exact point where each section begins and ends. The video clips for the following sections are video taping using a V8 video recorder.

Subsections of "Services/Directories" of "Passenger Services"

- Art

- Gardens

- Viewing Decks

- Shopping 
- Information/Foreign Currency Exchange

The subtitle of these video clips are generated by the following procedures:

1. Write the manuscript for each video section.

2. Choose the background music

3. While watching the recorded video played (without audio playback) from a VCR with a TV. The manuscript reader reads the manuscript to a microphone connected to a Macintosh Quadra 800 with Media Vision's Pro AudioSpectrum16 board installed. I use the Sound Edit Pro software from MacroMedia and the AudioSpectrum 16 audio digitizing board to digitize and record the subtitle into the hard disk of the Macintosh Quadra 800.

4. Connect the line output of a stereo system to AudioSpectrum 16's audio input. Play the background music with the stereo system and digitize the background music with Sound Edit Pro and AudioSpectrum 16.

5. Using the Sound Edit Pro's edit functions to perform the following tasks: 
a. Reduce the noise in the manuscript's recording by editing the waveforms of the sound file.

b. Import two waveforms into the same sound file.

c. Combine the manuscript and the background music's recording with proper synchronization into one sound file.

6. Combine the video from video recorder and the subtitle from Quadra 800 into one video tape.

7. Record and digitize the video tape above using JMC-550 into PC's hard drive.

All video clips are added to MDK's video library.

\subsubsection{Button Art Work}

Each button is composed of two parts: the original bitmap and a pushed down bitmap. All the buttons except video playback controls in this application are generated using Macintosh Quadra 800 with Canvas

3.5.3 as drawing tool. The procedures are as follows:

1. Collect loyal free clip arts from clip art CD.

2. Draw a button for the original state: 


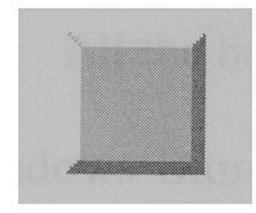

3. Draw a pushed down button:

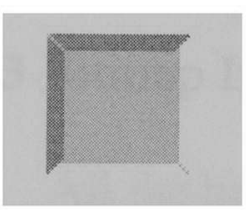

4. Combine clip arts with images above and generate one button's

two states.

Here are some of the buttons generated from procedures above.

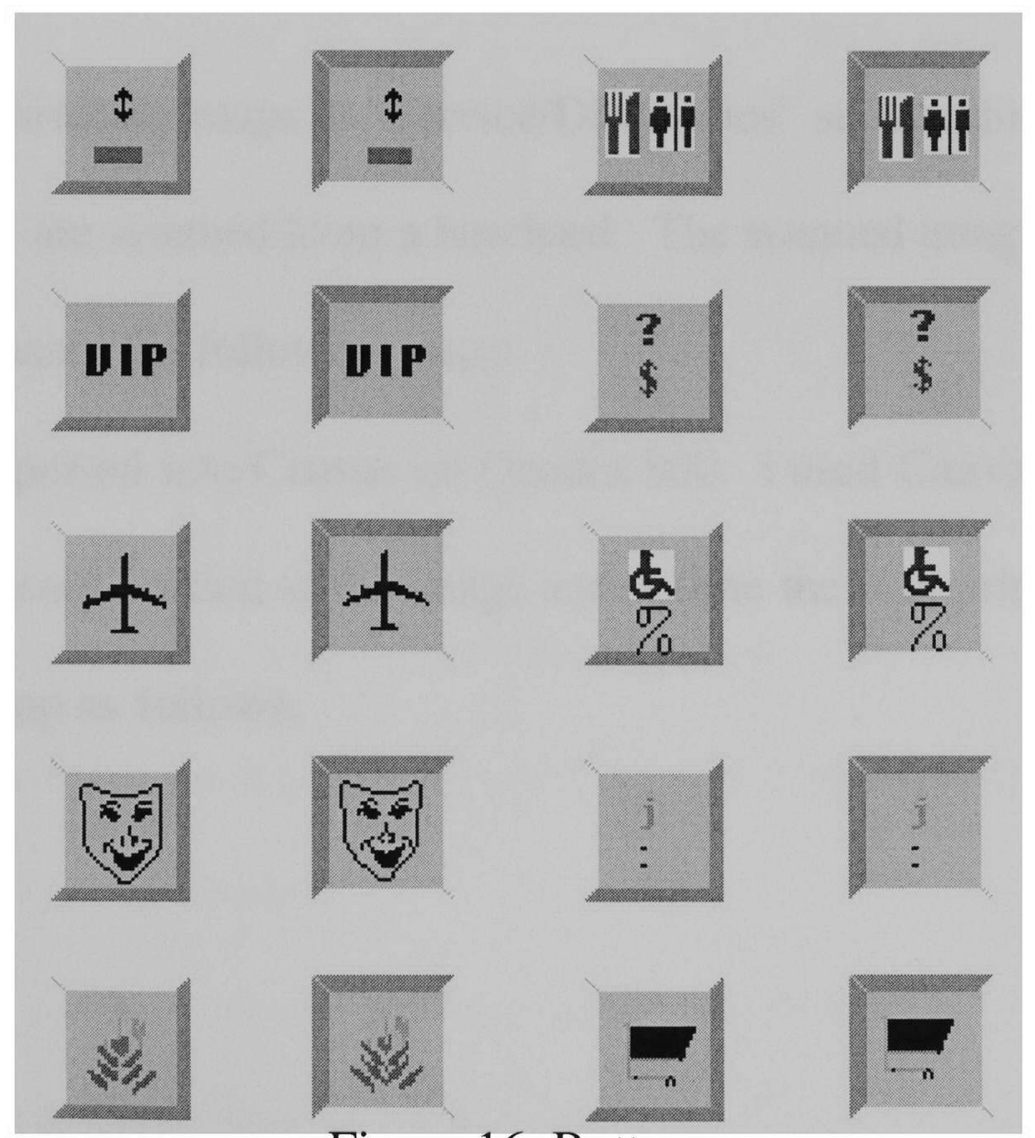

Figure 16. Buttons 
All the buttons bitmap images are converted into MicroSoft Windows Bitmap format and transferred to the PC's hard drive and then added to the MDK Button Library.

\subsubsection{Bitmap Image Art Work}

All the background images are selected from Walnut Creek

CDROM's clips art images CD. They are imported into Canvas 3.5.3 on the Quadra 800 to be resized so it will fit $640 \times 480$ PC monitor resolution.

The directory maps in "Service/Directories" section and it's subsections are scanned from a burchard. The scanned image are processed using the following steps:

1. Imported into Canvas on Quadra 800. I used Canvas to erase the unnecessary portion of the image and outline the blue print of the directory map as follows. 


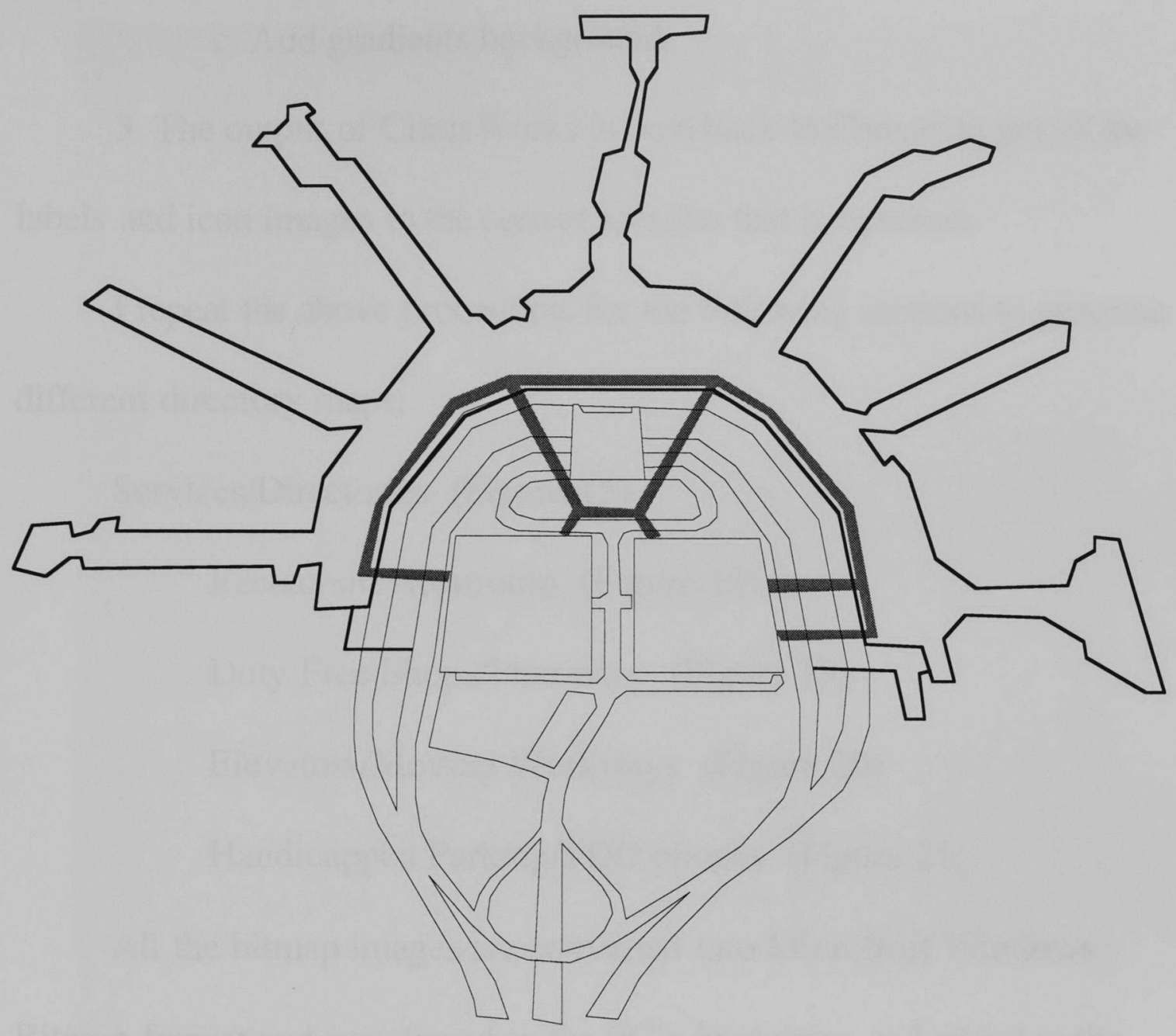

Figure 17. Directory map template

The above is the template for each directory sections.

2. The template is imported into ClarisWorks' drawing tool to accomplish the following:

a. Create the correct size $(640 \times 480)$ of bitmap image.

b. Add different colors to represent different areas. 
c. Add gradients background.

3. The output of ClarisWorks is read back to Canvas to put all the labels and icon images to the correct location that it represent.

I repeat the above procedures for the following sections to generate different directory maps:

Services/Directories (Figure 15)

Restaurants/Restroom (Figure 18)

Duty Free Shops/Pharmacy (Figure 19)

Elevators/Moving Workways (Figure 20)

Handicapped Parking/TDD phones (Figure 21)

All the bitmap images are converted into MicroSoft Windows

Bitmap format and transferred to the PC's hard drive and added to the MDK Bitmap Library. 


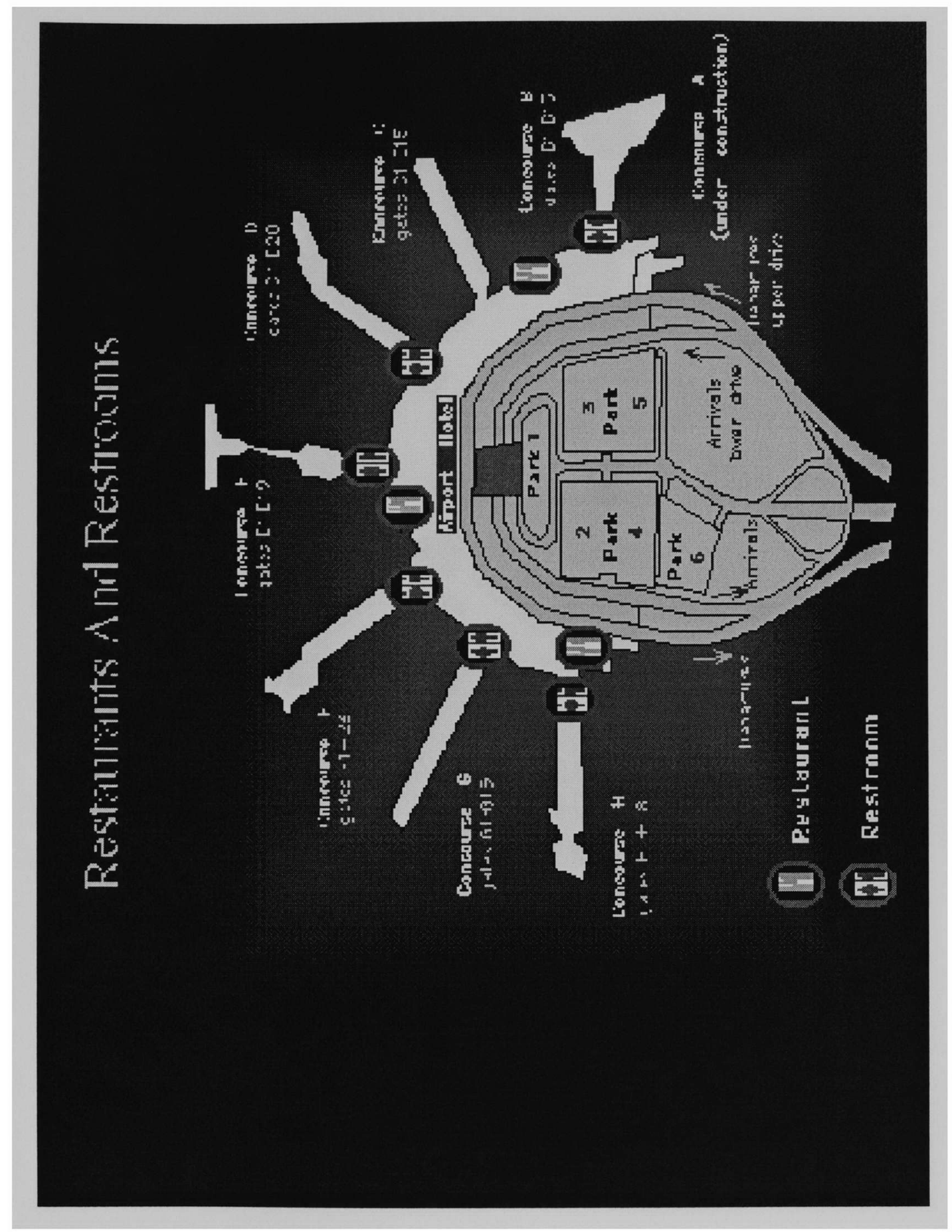

Figure 18. Restaurants and Restroom directory map 


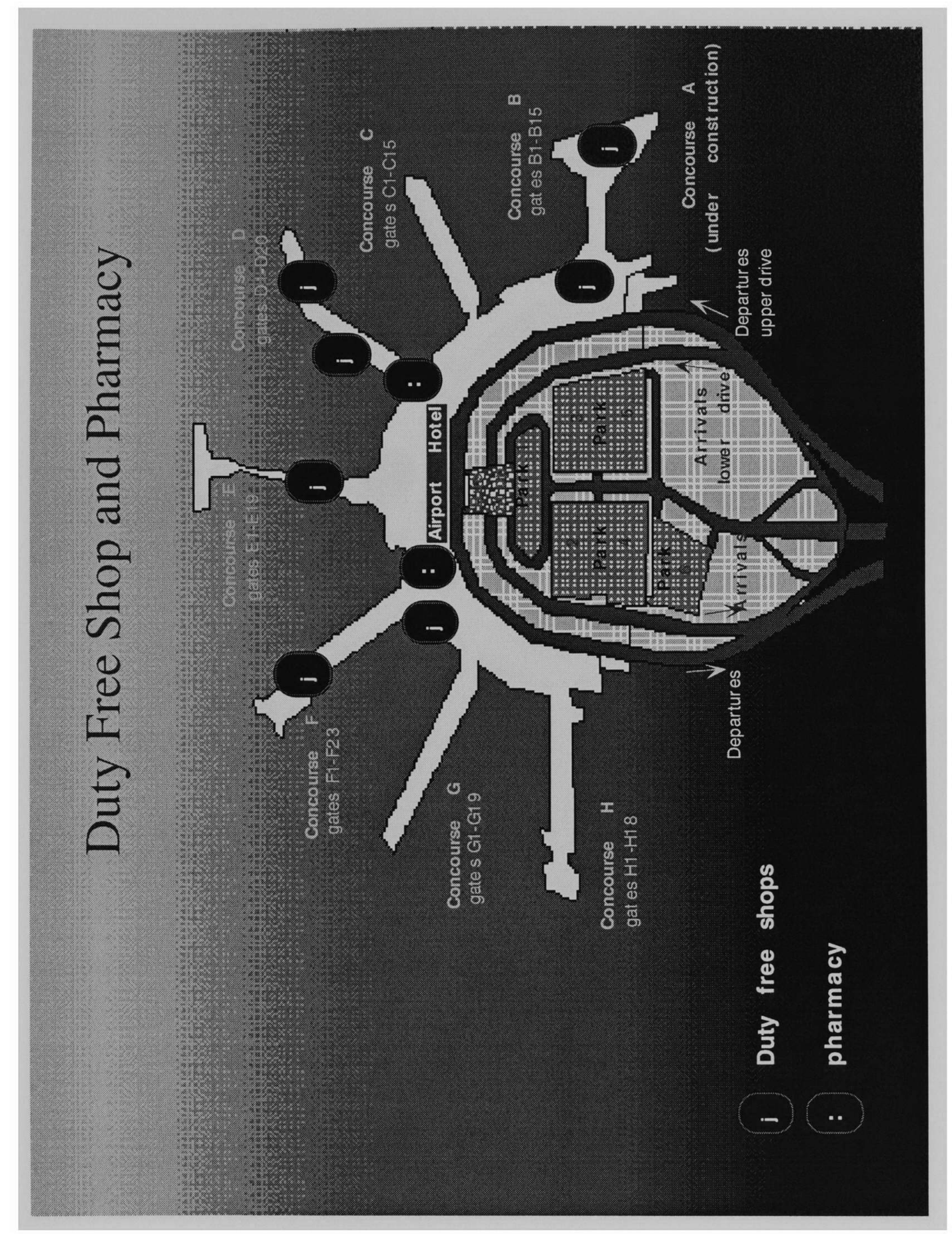

Figure 19. Duty Free Shop and Pharmacy directory map. 


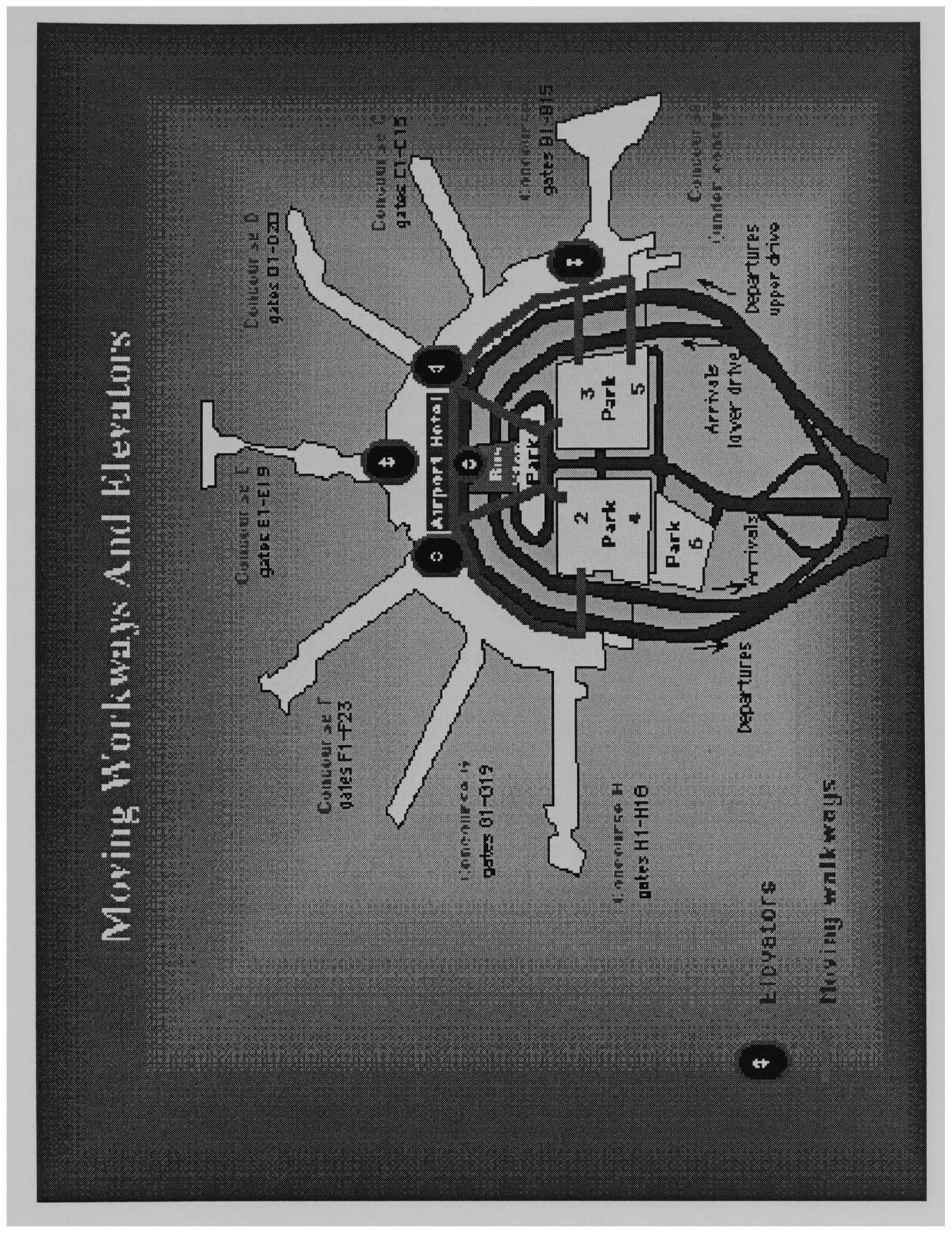

Figure 20. Moving Workway and Elevators directory map 


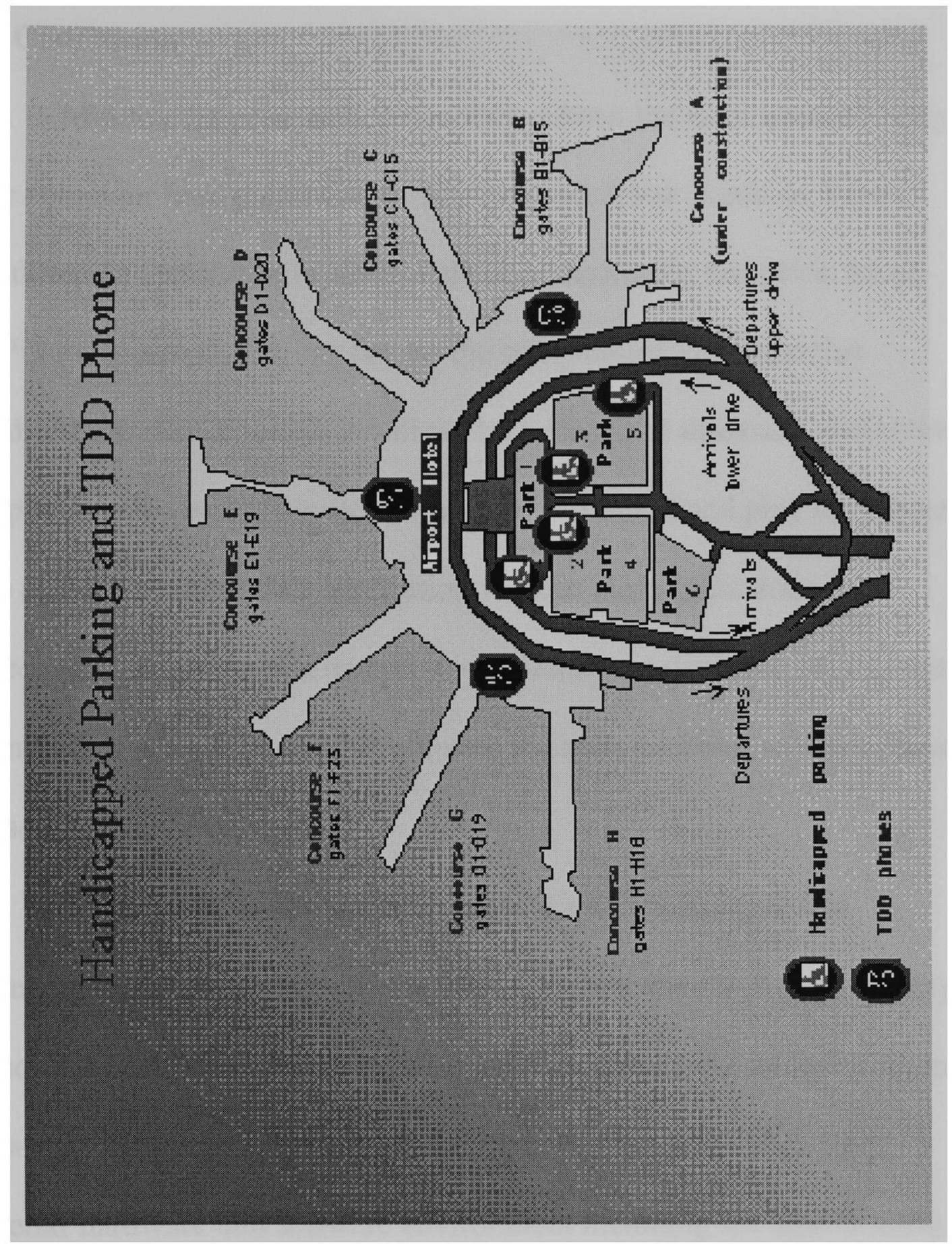

Figure 21. Handicapped Parking and TDD Phone directory map. 


\section{Conclusion}

Multimedia presentation has always been the most attractive way for computer base presentation. The most common bottle neck for multimedia application is always about performance and price. Most CPU today simply can not handle the computation condition that audio/video data required; it will not be a surprised that most audio/video application today has limited screen size, resolution and play back speed. To achieve a multimedia application without these limitations, a secondary processor that designed specifically for JPEG or MPEG data handling is a most reasonable solution for such problem which in most cases, are very expensive.

What we have designed and prototyped is an inexpensive integrated and comprehensive multimedia application with high quality resolution and play back performance for audio/video data on a popular low-end PC platform running Microsoft Windows and DOS. The overall hardware and software environment including the add-on card, PC, and software packages and tools could only cost below $\$ 2,500$, which is clearly one of ideal standalone multimedia system and 
multimedia front-end in a networked environment or for a powerful

server. Our study is an important step toward bringing the state of the arts technologies to every corner of our life. 


\section{REFERENCES}

Adam, J. A. (1993). Applications, implications: if the computer does for images and sound what it has done for text and equations, the result

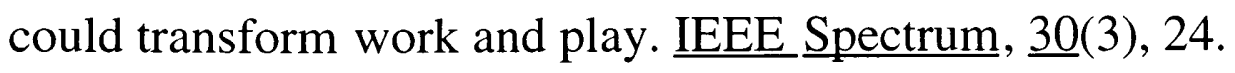

Benimoff, N. I. (1993). Multimedia user interfaces for telecommunications products and services. AT\&T Technical Jounal, $\underline{72}(3), 42$.

Berger, L. A. R. a. D. A. (1996). The Berkeley Distributed Video-on-Demand System. Berkeley Multimedia Research Center, 1996 publication.

Bloor, R. (1993). The evolution of the User Interface. DBMS, $\underline{6}(9), 10$.

Cole, B. (1993). The technology framework: lack of standards and the huge bandwidth appetite of full-motion multimedia are very present obstacles but won't be for long. (Special Report/Multimedia). $\underline{\text { IEEE }}$ 


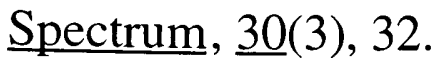

Davenport, W. E. M. a. G. (1989). Virtual Video Editing in Interactive Multimedia Applications. Communications of the ACM, $\underline{32}(7)$, 802-810.

Dixon, D. (1989). Life Before the Chips: Simulating Digital Video Interactive Technology. Communications of the ACM, $\underline{32}$ (7), 824-831.

Donly, T. C. (1993, Sept. 27). A major market in the making.

(Emerging Technologies for Resellers on the Cutting Edge:

Opportunities in Multimedia). Computer Reseller News, p. S6.

FOX, E. A. (1989). The Coming Revolution in Interactive Digital Video. Communications of the $\underline{\mathrm{ACM}}, \underline{32}, 795-801$.

Hwang, D. ( 1993, Sept 27). Big business, big breakthroughs; corporate customers are attracted by the visual appeal of the latest applications. 
(Emerging Technologies for Resellers on the Cutting Edge:

Opportunities in Multimedia). Computer Reseller News, p. S21.

LaPlante, A. (1993, Sept. 27). Image building: when less is more;small companies tap new products that show and tell. (Emerging Technologies for Resellers on the Cutting Edge: Opportunities in Multimedia).

Computer Reseller News, p. S15.

Microsystems, C.-C. (1992). JPEG File Interchange Format Version 1.02 No. C-Cube Microsystems.

Ripley, G. (1989). DVI - A Digital Multimedia Technology.

Communications of the ACM, $\underline{32}(7), 811-822$.

Robichaux, M. (1993, June 8). Cable-TV players continue to choose high-tech partners. The Wall Street Journal, p. pB8(W) pB8(E) col 4 (13 col in ). 
Roger L.Fetterman, S. K. G. (1993). Mainstream Multimedia: applying Multimedia in business ( 1 ed.). New York: Van Nostrand Reinhold.

Rosenthal, S. (1993, Aug. 23). Building a better ATM. (Asynchronous Transfer Mode). MacWeek, p. 28.

Rowe, L. A. (1995). Video Compression for Desktop Applicatoins. Berkeley Multimedia Research Center, 1995 publication.

Sims, D. (1994). Multimedia camp empowers disabled kids. (educational authoring software). IEEE Computer Graphics and Applications, $14(1), 13$.

Wallace, G. (April 1991). The JPEG Still Picture Compression Standard. Communications of the ACM, 34(4), 30-44.

Waurzyniak, P. (1993, April). Encarta: explore new worlds from the desktop. Byte, p. 55 . 